\title{
Hybrid Composite Membrane of Phosphorylated Chitosan/ Poly (Vinyl Alcohol)/Silica as a Proton Exchange Membrane
}

\author{
Nur Adiera Hanna Rosli ${ }^{1}$, Kee Shyuan Loh ${ }^{1, * \mathbb{C}}$, Wai Yin Wong ${ }^{1}{ }^{(\mathbb{C}}$, Tian Khoon Lee ${ }^{2}{ }^{\mathbb{D}}$ and Azizan Ahmad ${ }^{2}$ \\ 1 Fuel Cell Institute, Universiti Kebangsaan Malaysia, Bangi 43600, Selangor, Malaysia; \\ adierahanna@gmail.com (N.A.H.R.); waiyin.wong@ukm.edu.my (W.Y.W.) \\ 2 Faculty of Science and Technology, Universiti Kebangsaan Malaysia, Bangi 43600, Selangor, Malaysia; \\ edison_tiankhoon@hotmail.com (T.K.L.); azizan@ukm.edu.my (A.A.) \\ * Correspondence: ksloh@ukm.edu.my
}

check for updates

Citation: Rosli, N.A.H.; Loh, K.S.; Wong, W.Y.; Lee, T.K.; Ahmad, A. Hybrid Composite Membrane of Phosphorylated Chitosan/ Poly (Vinyl Alcohol)/Silica as a Proton Exchange Membrane. Membranes 2021, 11, 675. https://doi.org/ 10.3390/membranes11090675

Academic Editors: Young Eun Song and Aruna Kumar Mohanty

Received: 4 June 2021

Accepted: 30 August 2021

Published: 31 August 2021

Publisher's Note: MDPI stays neutral with regard to jurisdictional claims in published maps and institutional affiliations.

Copyright: (C) 2021 by the authors. Licensee MDPI, Basel, Switzerland. This article is an open access article distributed under the terms and conditions of the Creative Commons Attribution (CC BY) license (https:/ / creativecommons.org/licenses/by/ $4.0 /)$.

\begin{abstract}
Chitosan is one of the natural biopolymers that has been studied as an alternative material to replace Nafion membranes as proton change membranes. Nevertheless, unmodified chitosan membranes have limitations including low proton conductivity and mechanical stability. The aim of this work is to study the effect of modifying chitosan through polymer blending with different compositions and the addition of inorganic filler on the microstructure and physical properties of $\mathrm{N}$-methylene phosphonic chitosan/poly (vinyl alcohol) (NMPC/PVA) composite membranes. In this work, the NMPC biopolymer and PVA polymer are used as host polymers to produce NMPC/PVA composite membranes with different compositions (30-70\% NMPC content). Increasing NMPC content in the membranes increases their proton conductivity, and as NMPC/PVA-50 composite membrane demonstrates the highest conductivity $\left(8.76 \times 10^{-5} \mathrm{~S} \mathrm{~cm}^{-1}\right.$ at room temperature), it is chosen to be the base membrane for modification by adding hygroscopic silicon dioxide $\left(\mathrm{SiO}_{2}\right)$ filler into its membrane matrix. The loading of $\mathrm{SiO}_{2}$ filler is varied (0.5-10 wt.\%) to study the influence of filler concentration on temperature-dependent proton conductivity of membranes. NMPC/PVA-SiO (4 wt.\%) exhibits the highest proton conductivity of $5.08 \times 10^{-4} \mathrm{~S} \mathrm{~cm}^{-1}$ at $100{ }^{\circ} \mathrm{C}$. In conclusion, the study shows that chitosan can be modified to produce proton exchange membranes that demonstrate enhanced properties and performance with the addition of $\mathrm{PVA}$ and $\mathrm{SiO}_{2}$.
\end{abstract}

Keywords: polymer blending; $N$-methylene phosphonic chitosan; poly (vinyl alcohol); silicon dioxide filler; proton exchange membranes

\section{Introduction}

Nafion membranes have been commercially used as proton exchange membranes (PEMs) due to their high proton conductivity under hydrated conditions and good thermal and chemical stability. Nonetheless, aside from these advantages, Nafion membranes still have several shortcomings, including the high-cost of its materials, intense methanol crossover, and a severely decreased proton conductivity under low humidity conditions [1]. Moreover, the operation of PEMFC with the use of Nafion membrane was limited to low operating temperature $\left(\approx 80^{\circ} \mathrm{C}\right)[2,3]$. Permanent hydration and gas humidification were needed to ensure high proton conductivity [4]. However, as the temperature exceeded 100 ${ }^{\circ} \mathrm{C}$, the affinity with water and mechanical stability of Nafion membrane will be reduced [3]. Hence, various studies have been carried out over the years testing various biopolymer materials as alternative membrane materials to replace Nafion membranes.

Chitosan is a biopolymer material that has been considered an alternative material due to its hydrophilicity, biodegradability, biocompatibility, and low-cost. Additionally, due to the presence of free amine and hydroxyl groups in its backbone, chitosan can be chemically modified to produce functionalized chitosan composite membranes. Nonetheless, there are limitations that pristine chitosan membranes suffer from, namely, their comparatively poor mechanical properties and low proton conductivity $\left(\sim 10^{-9} \mathrm{~S} \mathrm{~cm}^{-1}\right)$ under dry conditions 
and at room temperature because a small number of protons dissociated by moisture from the air in the chitosan matrix cannot move freely [5,6]. Numerous studies have been conducted and reported regarding chitosan modifications for developing enhanced chitosan membranes; these modifications include the addition of inorganic fillers, sulfonation, phosphorylation, quaternization, chemical cross-linking methods and blending with other polymers. One of the most popular modification methods that has been used over the past decade is the phosphorylation method. Wan et al. and Jayakumar et al. [7,8] reported that phosphorylated chitosan membranes could be prepared through the reaction of orthophosphoric acid and urea in $N, N$-dimethylformamide, as urea could promote the reaction, in which the produced functionalized membrane exhibited a decrease in its crystalline structure due to the increase in phosphorus content. In addition, $N$-methylene phosphonic chitosan (NMPC) was produced by Ramos et al., Binsu et al., Saxena et al., and Datta et al. [9-12] through a reflux method, whereas Dadhich et al. [13] produced NMPC by using a microwave-assisted rapid synthesis through a Mannich-type reaction. The produced NMPC had enhanced ionogenic and solubility properties without altering its filmogenic properties, allowing NMPC to be selected as a PEM for use in fuel cell applications $[10,12,14]$.

The incorporation of inorganic materials into polymers has been extensively studied by past researchers. The addition of hygroscopic fillers, such as silicon dioxide $\left(\mathrm{SiO}_{2}\right)$, titanium dioxide $\left(\mathrm{TiO}_{2}\right)$ [15-17], and tungsten trioxide $\left(\mathrm{WO}_{3}\right)[18,19]$, into the PEM matrix can affect the physicochemical properties of host matrix, including in improving mechanical properties [18], increasing the water retention capacity and proton conductivity of polymer composites by forming alternative proton conduction pathways [15-17]. Vijayalekshmi and Khastgir [20] studied and produced a series of chitosan-based nanocomposites with the addition of sulfonated polyaniline/nanosilica $\left(\mathrm{sPAni} / \mathrm{SiO}_{2}\right)$ to be used as proton exchange membranes. This CS-sPAni $/ \mathrm{SiO}_{2}$ nanocomposite membrane showed a high protons conductivity of $8.39 \times 10^{-3} \mathrm{~S} \mathrm{~cm}^{-1}$; additionally, the presence of $\mathrm{SiO}_{2}$ as an inorganic filler in the membrane enhanced the water uptake, improved proton transport, and provided additional pathways for proton conduction, which improved the proton conductivity [20]. Other than that, graphene oxide (GO), which is an active nanofiller [21,22] and could be modified with various functional groups $[23,24]$, have been used in recent studies, in which the developed sulfonated graphene oxide (SGO) could enhance the proton conduction of polymeric membranes as well as provide continuous pathway for facile proton transport in the membranes [25,26]. Similarly, Bai et al. [27] synthesized phosphorylated graphene oxide (PGO), by allowing a polymeric layer bearing phosphonic acid (PA) groups as proton carriers covered onto GO surface, which contributed to the formation of efficient proton transfer channels along the membranes and achieved desired proton conductivity. The resultant membranes exhibited enhanced proton conductivity, thermal and mechanical stability [27].

Another method to improve the physical properties of chitosan membranes was through polymer blending with synthetic and natural polymer membranes. Several synthetic polymers, such as poly(vinyl alcohol) (PVA), poly(vinylidene fluoride) (PVDF), polyethersulfone (PES), polysulfone (PS), poly(ethylene oxide), polycaprolactone, and polyacrylamide, have been blended with chitosan to form composite membranes in previous studies. Blended membranes that undergo a cross-linking process demonstrate further improvements to their mechanical properties and water retention capacity [28]. The most common candidate that has been widely used to combine with chitosan membranes is PVA due to its unique properties, including its high crystallinity, water solubility, good filmforming ability, and high hydrophilicity due to containing reactive functional groups of -OH and forming hydrogen bonds that allowed chemical modification [29-31]. There have been several previous studies regarding the preparation of PVA/chitosan-blended membranes for fuel cell applications. PVA/chitosan and quaternized chitosan/quaternized PVA blended membranes have been prepared and cross-linked, exhibiting enhanced mechanical stability, methanol permeability, and proton conductivity and showing their potential 
use in direct methanol, anion exchange membranes and alkaline direct methanol fuel cell applications [32-34]. El Miri et al. [35] reported on the preparation and characterization of PVA/chitosan polymeric blends with the addition of cellulose nanocrystals, which act as nanoreinforcing agents, and this well-mixed membrane exhibited improved properties, including mechanical and thermal stability.

This study focuses on developing composite membranes containing the NMPC biopolymer and PVA polymer as the main hosts. These two polymers are mixed to form homogeneous solutions, which are then cast through the solution casting method and crosslinked to form NMPC/PVA composite membranes. The NMPC biopolymer is synthesized through the reflux method, while the used PVA polymer is commercially produced. The NMPC/PVA composite membranes are prepared with different compositions by varying the polymer ratios. A series of NMPC/PVA composite membranes modified with different loadings of $\mathrm{SiO}_{2}$ are prepared through the same solution casting method. The structural properties and the thermal and mechanical stability of these composite membranes are characterized by FTIR, XRD, FESEM, TGA, and DMA techniques. These membranes are also studied for their water uptake, swelling ratio, ion-exchange capacity, and proton conductivity to investigate the effect of polymer blending as well as the addition of $\mathrm{SiO}_{2}$ filler in the membranes at the low operating temperature $\left(80-100{ }^{\circ} \mathrm{C}\right)$. The results of this study demonstrate that modifying chitosan through polymer blending and the addition of an inorganic filler, $\mathrm{SiO}_{2}$, produces composite membranes with enhanced performance when compared with the pure, unmodified NMPC membrane.

\section{Materials and Methods}

\subsection{Materials}

Commercial chitosan with a low molecular weight (50,000-190,000 Da, 75-85\% deacetylated), phosphorous acid (99\%), poly(vinyl alcohol) (Mw: 85,000-124,000, 99+\% hydrolyzed), and silicon dioxide nanopowder (10-20 nm particle size (BET), 99.5\%) were purchased from Sigma-Aldrich. Glacial acetic acid (99\%), formaldehyde (37-40\%), acetone (AR grade), sodium sulfate anhydrous (AR grade), and hydrochloric acid (37\%, AR grade) were supplied by Systerm (Shah Alam, Selangor, Malaysia). Sodium hydroxide, sodium chloride, and phenolphthalein were obtained from R\&M Chemicals (Petaling Jaya, Selangor, Malaysia). Sulfuric acid (95-97\%) was procured from Merck (Kenilworth, NJ, USA). All materials were used without further purification. Deionized water was used throughout the whole experiment.

\subsection{Synthesis of N-Methylene Phosphonic Chitosan (NMPC)}

N-Methylene phosphonic chitosan (NMPC) was synthesized according to a previously reported phosphorylation method $[9,10]$. A chitosan solution was prepared by dissolving $5 \mathrm{~g}$ of chitosan powder in $250 \mathrm{~mL}$ of $1 \%(v / v)$ glacial acetic acid. Then, the solution was poured into a three-necked round-bottom flask with a magnetic stirrer and thermometer as well as a reflux condenser. The solution was then refluxed and heated with continuous stirring. The solution was heated continuously until the temperature reached $60{ }^{\circ} \mathrm{C}$. Next, $2.5 \mathrm{~g}$ of phosphorous acid was dissolved in $25 \mathrm{~mL}$ of deionized water before being slowly added to the above solution. The heating process was continued until the temperature reached $70{ }^{\circ} \mathrm{C}$, and $2.5 \mathrm{~mL}$ of formaldehyde was gradually added into the solution. The temperature of the solution was maintained for $8 \mathrm{~h}$ at $70{ }^{\circ} \mathrm{C}$. The produced pale, yellow solution was then cooled to room temperature overnight. Acetone was excessively added into the solution until a white polymer precipitate was formed, which was the NMPC polymer. The resulting precipitate was filtered and washed with acetone in a Soxhlet apparatus for $24 \mathrm{~h}$ to remove unreacted phosphorous acid. Finally, the precipitate was dried in a desiccator. 


\subsection{Preparation of the N-Methylene Phosphonic Chitosan/Poly (Vinyl Alcohol) Composite Membrane}

The N-methylene phosphonic chitosan/poly (vinyl alcohol) (NMPC/PVA) composite membranes were prepared by the solution casting method [10]. NMPC and PVA solutions were prepared by separately dissolving their respective compounds in known amounts of water before producing various compositions of NMPC/PVA composite membranes. Then, both solutions were mixed dropwise under continuous stirring for $5 \mathrm{~h}$ at room temperature. Air bubbles that formed in the solution were removed by sonication to obtain a clear solution, which was then cast onto a clean glass petri dish and dried for 4 days at $60{ }^{\circ} \mathrm{C}$. The resulting dried membranes (films) were further subjected to cross-linking through immersion in a solution containing formaldehyde $(54.1 \mathrm{~g})$, sodium sulfate $(150.0 \mathrm{~g})$, sulfuric acid $(125.0 \mathrm{~g})$, and water $(470.0 \mathrm{~g})$ for $2 \mathrm{~h}$ at $60^{\circ} \mathrm{C}$. Next, the cross-linked films were washed with deionized water to remove the unreacted cross-linking agents and were further dried at ambient temperature for $24 \mathrm{~h}$. The obtained membranes were designated NMPC/PVA-X, where $X$ was the NMPC content $(\%, w / w ; 30-70 \%)$ in the membrane phase. The content range of NMPC/PVA membranes was determined based on the preliminary studies that have been conducted. The membrane samples were kept in a desiccator to avoid exposure to moisture before further characterization.

\subsection{Preparation of the N-Methylene Phosphonic Chitosan/Poly (Vinyl Alcohol) Composite Membrane Modified with Silicon Dioxide Filler (NMPC/PVA-SiO $\left.{ }_{2}\right)$}

$\mathrm{NMPC} / \mathrm{PVA}-\mathrm{SiO}_{2}$ composite membranes were prepared through the same solution casting method as the NMPC/PVA composite membrane. The effect of a hygroscopic material on the NMPC/PVA composite membrane was studied by adding $\mathrm{SiO}_{2}$ filler into the polymer solution. The NMPC/PVA-50 composite membrane with the highest proton conductivity value was selected as the base membrane to conduct this study. $\mathrm{SiO}_{2}$ powder was dispersed into the NMPC/PVA polymer solution at a ratio of 50:50 $(\%, w / w)$ using a sonication process in a water bath and stirred continuously with different $\mathrm{SiO}_{2}$ loadings $(0.5,1,2,4,6,8$, and $10 \mathrm{wt} . \%)$ until becoming homogeneous. The basis for the selection of $\mathrm{SiO}_{2}$ loadings range was determined based on the range that was commonly used in the preliminary studies. The solution was then poured into a glass Petri dish and dried for 4 days at $60^{\circ} \mathrm{C}$, and all the resulting NMPC/PVA-SiO ${ }_{2}$ composite membranes underwent a cross-linking process before characterization was conducted.

\subsection{Characterization}

\subsubsection{Fourier Transform Infrared (FTIR) Spectroscopy}

FTIR analysis was conducted using a Perkin Elmer Spectrum 400 FTIR/NIR spectrometer (Perkin Elmer, Ohio, USA) in attenuated total reflectance (ATR) mode in the wavenumber region of $4000-650 \mathrm{~cm}^{-1}$ with a scan resolution rate of $4 \mathrm{~cm}^{-1}$ at room temperature condition. FTIR studies were performed to determine the functional groups of the pristine chitosan and NMPC powder, as well as the produced composite membranes.

\subsubsection{X-ray Diffraction (XRD)}

X-ray diffraction was performed using a Bruker D8 Advance diffractometer to determine the crystallinity of the pristine chitosan, NMPC powder, silicon dioxide nanopowder (commercially purchased), along with the resulting composite membranes. The diffractograms were measured with $\mathrm{Cu}-\mathrm{K}_{\alpha}$ radiation (wavelength of radiation $=0.15405 \AA$ ) at diffraction angles $(2 \theta)$ in the range of $5-80^{\circ}$. The crystallinity and amorphous phases of the polymer and membrane samples were measured using Bruker Diffrac EVA XRD software (Bruker, Massachusetts, USA).

\subsubsection{Field-Emission Scanning Electron Microscopy (FESEM)}

The cross-sectional morphologies of the NMPC membrane, NMPC/PVA and NMPC/ $\mathrm{PVA}-\mathrm{SiO}_{2}$ composite membranes were observed using field-emission scanning electron mi- 
croscopy (FESEM, Zeiss SUPRA 55VP, Jena, Germany). The instrumentation was equipped with an element mapping energy-dispersive X-ray spectroscopy (EDX) analyzer to observe the homogeneity and distributions of elements on the modified composite membranes according to the predetermined filler compositions. Before the analysis was performed, all samples will be deposited with gold or carbon through vacuum spraying to form an ultra-thin flow layer without changing the morphological structure of the samples and the samples were analyzed at magnification level of $1000 \times$.

\subsubsection{Thermogravimetric Analysis (TGA)}

A thermogravimetric analyzer (Perkin Elmer STA 6000, Akron, OH, USA) was used to determine the thermal stability and thermal degradation process of the membranes in a nitrogen atmosphere at a heating rate of $10{ }^{\circ} \mathrm{C} \mathrm{min}^{-1}$ from $30-600{ }^{\circ} \mathrm{C}$.

\subsubsection{Dynamic Mechanical Analysis (DMA)}

Mechanical strength analysis of the membranes was conducted under isothermal conditions using a dynamic mechanical analyzer (Perkin Elmer DMA 8000, Akron, OH, USA) at a frequency of $1 \mathrm{~Hz}$ and a heating rate of $3^{\circ} \mathrm{C} \mathrm{min}{ }^{-1}$ from $25-200{ }^{\circ} \mathrm{C}$.

\subsubsection{Water Uptake and Swelling Ratio}

For the measurement of water uptake, the membrane samples were dried at room temperature for a few days, and their weights were measured continuously for 3 days to ensure that the membrane's weight is constant. Then, the membranes were immersed in deionized water for $24 \mathrm{~h}$ at room temperature. The membranes were wiped off with tissue paper, and excess surface water was removed. The weight of the wet membranes was measured, and the weight differences before and after hydration in relation to the weight of the dry membranes were calculated as the water uptake percentage using Equation (1):

$$
\text { Water uptake }(\%)=\frac{W_{\text {wet }}-W_{\text {dry }}}{W_{\text {dry }}} \times 100
$$

where $W_{\text {wet }}$ is the weight of membranes after being immersed in deionized water and $W_{\text {dry }}$ is the initial weight of dry membranes.

The swelling ratio of the membrane samples was measured by measuring the change in surface area and thickness before and after hydration. The thickness of the membranes was measured with a micrometer, and the swelling ratios were calculated from Equations (2) and (3), respectively:

$$
\begin{gathered}
\text { Swelling area }(\%)=\frac{\mathrm{A}_{\text {wet }}-\mathrm{A}_{\text {dry }}}{\mathrm{A}_{\mathrm{dry}}} \times 100 \\
\text { Swelling thickness }(\%)=\frac{\mathrm{T}_{\text {wet }}-\mathrm{T}_{\text {dry }}}{\mathrm{T}_{\text {dry }}} \times 100
\end{gathered}
$$

where $A_{\text {wet }}$ and $T_{\text {wet }}$ represent the surface area and thickness of the membranes after being immersed in deionized water, respectively. $A_{d r y}$ and $T_{d r y}$ are the initial surface area and thickness of dry membranes, respectively. The average value of swelling area and thickness was measured from three measurements.

\subsubsection{Ion-Exchange Capacity (IEC)}

The ion-exchange capacity (IEC) of the membrane samples was determined through the usual acid-base titration method. The membranes were equilibrated in $1.0 \mathrm{M} \mathrm{HCl}$ solution for $24 \mathrm{~h}$ to convert the membrane into the $\mathrm{H}^{+}$form. The membranes were then washed with deionized water to remove excess $\mathrm{HCl}$. Next, the membranes were equilibrated in $0.1 \mathrm{M} \mathrm{NaCl}$ solution for $24 \mathrm{~h}$ and titrated against a $0.1 \mathrm{M} \mathrm{NaOH}$ solution by using 
phenolphthalein as the universal indicator. The IEC (mequiv $\mathrm{g}^{-1}$ ) values were calculated using Equation (4):

$$
\mathrm{IEC}=\frac{\mathrm{V}_{\mathrm{NaOH}} \times \mathrm{C}_{\mathrm{NaOH}}}{\mathrm{W}_{\mathrm{dry}}}
$$

where $\mathrm{V}_{\mathrm{NaOH}}$ is the volume of $\mathrm{NaOH}$ used, $\mathrm{C}_{\mathrm{NaOH}}$ is the concentration of $\mathrm{NaOH}$ and $\mathrm{W}_{\mathrm{dry}}$ is the initial weight of dry membranes.

\subsubsection{Proton Conductivity}

The proton conductivity of the membrane samples was measured at room temperature for NMPC membrane and NMPC/PVA composite membranes, whereas the conductivity of NMPC/PVA-SiO ${ }_{2}$ composite membranes was measured at the temperature of $25-100{ }^{\circ} \mathrm{C}$, under hydrated conditions. The proton conductivity was measured by electrochemical impedance spectroscopy (EIS) using an electrochemical workstation (Autolab PGSTAT $128 \mathrm{~N}$, Utrecht, The Netherlands) and a signal amplitude of $10 \mathrm{mV}$ over a frequency range of $1 \mathrm{~Hz}$ to $1 \mathrm{MHz}$. The membrane samples were immersed in deionized water for $24 \mathrm{~h}$ at room temperature and then placed into a clamp and connected by two platinum electrodes. The measurements were made by placing a membrane disc with a diameter of $2 \mathrm{~cm}^{2}$ into a Teflon conductivity closed cell containing two stainless steel electrodes in a temperaturecontrolled chamber. A little amount of water in the cell maintained the relative humidity at $100 \%$. The proton conductivity was measured from room temperature, $25^{\circ} \mathrm{C}$ to $100^{\circ} \mathrm{C}$, and the samples were kept at each temperature for $15 \mathrm{~min}$ for the membrane to reach an equilibrium temperature [36,37]. The proton conductivity was determined from a Nyquist plot to obtain the bulk resistance of the membrane through the intersection of the highfrequency intercept with the real axis. The proton conductivity values were calculated using Equation (5):

$$
\sigma=\frac{\mathrm{t}}{\mathrm{R}_{\mathrm{b}} \times \mathrm{A}}
$$

where $t$ and $A$ are the thickness and area of the prepared membrane samples, respectively, and $R_{b}$ is the bulk resistance of the membrane samples. The proton conductivity values were the average of three measurements, and the standard deviation was calculated.

\section{Results and Discussion}

\subsection{Chitosan and N-Methylene Phosphonic Chitosan (NMPC)}

\subsubsection{FTIR and XRD Analysis}

The FTIR spectra of chitosan and NMPC are presented in Figure 1a (i and ii), which was conducted to determine and differentiate the chemical structures and bonds between both derivatives. The FTIR spectra of pristine chitosan (Figure S1A) showed a broad peak from $3500-3200 \mathrm{~cm}^{-1}$, which represented the overlapping $\mathrm{O}-\mathrm{H}$ and $\mathrm{N}-\mathrm{H}$ stretching bands [38]. The absorption peak at $2871 \mathrm{~cm}^{-1}$ (Figure S1A) was assigned to $\mathrm{C}-\mathrm{H}$ stretching, whereas the weak absorption peak at $1643 \mathrm{~cm}^{-1}$ corresponded to $\mathrm{C}=\mathrm{O}$ stretching due to amide carboxyl groups; additionally, the peak at $1584 \mathrm{~cm}^{-1}$ represented $\mathrm{N}-\mathrm{H}$ amine bending (Figure S1B). The peaks at 1422, 1376, and $1311 \mathrm{~cm}^{-1}$ (Figure S1B) were ascribed to $\mathrm{C}-\mathrm{N}$ stretching coupled with $\mathrm{N}-\mathrm{H}$ in-plane deformation, symmetric angular $-\mathrm{CH}_{3}$ bending, and $\mathrm{C}-\mathrm{N}$ stretching of the amino group, respectively [38,39]. The peak at $1149 \mathrm{~cm}^{-1}$ indicated C-O-C stretching, whereas the strong bands at $1065 \mathrm{~cm}^{-1}$ and $1026 \mathrm{~cm}^{-1}$ were attributed to the presence of $\mathrm{C}-\mathrm{O}$ stretching in the chitosan skeleton (Figure S1C) [12,38]. 


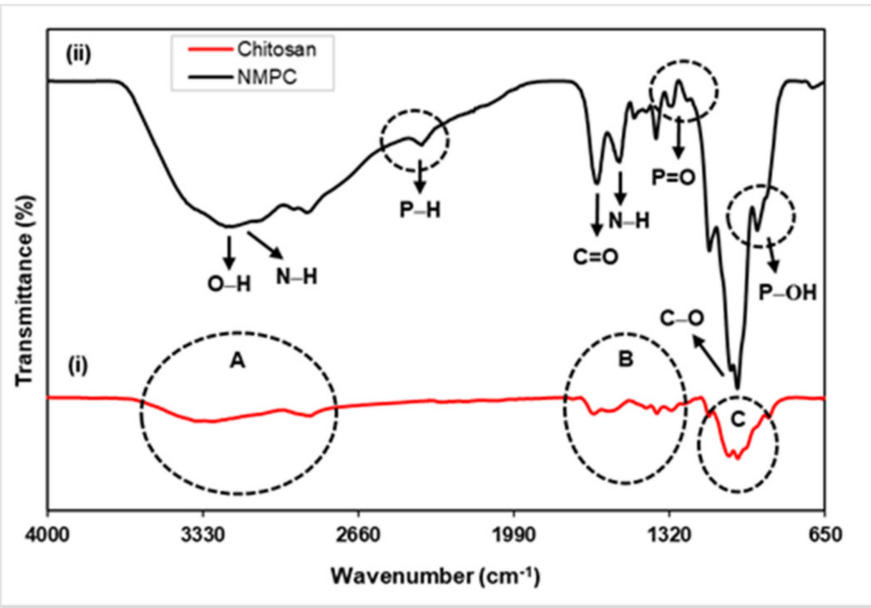

(a)

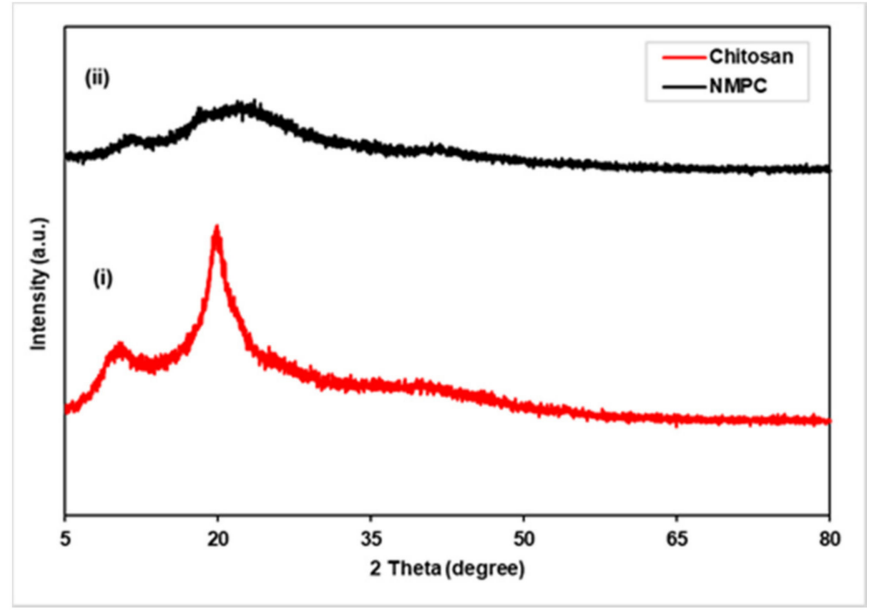

(b)

Figure 1. (a) FTIR spectra of chitosan and N-methylene phosphonic chitosan (NMPC) and (b) XRD diffractograms of chitosan and NMPC.

The FTIR spectra also represented the chemical bonds that existed in NMPC (Figure 1a (ii)), resulting from the phosphorylation of chitosan. The NMPC spectra showed the $\mathrm{O}-\mathrm{H}$ and $\mathrm{N}-\mathrm{H}$ stretching bands at $3500-3200 \mathrm{~cm}^{-1}$ broadened, implying the substitution of $-\mathrm{CH}_{2} \mathrm{PO}_{3} \mathrm{H}_{2}$ by the $\mathrm{H}$ atoms in the amine groups and affecting the hydrogen bonds [12,40]. The amine deformation peaks shifted to lower frequencies, from $1643 \mathrm{~cm}^{-1}$ and $1548 \mathrm{~cm}^{-1}$ in chitosan to $1632 \mathrm{~cm}^{-1}$ (antisymmetric deformation) and $1536 \mathrm{~cm}^{-1}$ (symmetric deformation) in NMPC; this result indicated the protonation of the chitosan amine as there was a hydrogen substitution to the methylene phosphonic groups that made it a tertiary amine and involved both peaks attributed to $\mathrm{NH}_{3}{ }^{+}$groups [12,39]. The new bands at $1243 \mathrm{~cm}^{-1}$ and $943 \mathrm{~cm}^{-1}$ were ascribed to $\mathrm{P}=\mathrm{O}$ and $\mathrm{P}-\mathrm{OH}$ stretching bands, whereas the peaks at $1470 \mathrm{~cm}^{-1}$ and $1380 \mathrm{~cm}^{-1}$ were assigned to $-\mathrm{CH}_{2}-$ vibrations of the methylene phosphonic groups in the molecule [12,39,41]. Moreover, the new peak at $2386 \mathrm{~cm}^{-1}$ indicated the $\mathrm{P}-\mathrm{H}$ stretching of phosphonic groups, and the existence of these new peaks proved the addition of methylene phosphonic groups into chitosan. In addition, the strong bands with high intensities at $1057 \mathrm{~cm}^{-1}$ and $1027 \mathrm{~cm}^{-1}$ implied that $\mathrm{C}-\mathrm{O}$ stretching overlapped with $\mathrm{P}-\mathrm{OH}$ stretching; thus, according to the FTIR analysis, the resultant NMPC was successfully synthesized through a phosphorylation method [39,41].

The phase composition and structure of pristine chitosan and NMPC were analyzed using XRD. The XRD diffraction pattern of pristine chitosan (Figure 1b (i)) showed that chitosan had semicrystalline properties, consisting of both amorphous and crystalline phases. The existence of a sharp peak at $2 \theta=19.90^{\circ}$ and another peak at $2 \theta=10.30^{\circ}$ showed a high degree of crystallization in chitosan. The high degree of crystallization in chitosan was due to intra- and extra-molecular hydrogen bonding [42].

The XRD spectrum of NMPC (Figure $1 \mathrm{~b}$ (ii)) showed reflections at $2 \theta$ values of $11.40^{\circ}$ and $21.80^{\circ}$, which were attributed to amorphous properties; additionally, these values were far from those found in chitosan and were representative of a novel structure that accommodated the bulky substituents. NMPC, which is a water-soluble derivative, has a high degree of amorphous phase and can reduce the crystallinity of chitosan; thus, the movement of the polymer chain segment can be enhanced and improve the proton conductivity values [43]. 


\subsection{N-Methylene Phosphonic Chitosan/Poly (Vinyl Alcohol) (NMPC/PVA) Composite Membranes}

\subsubsection{FTIR and XRD Analysis}

FTIR analyses were performed to identify the chemical structure of unmodified NMPC and PVA membranes and prepared NMPC/PVA composite membranes. Figure 2a,b shows the FTIR spectra of the NMPC and PVA membranes along with the NMPC/PVA-50 composite membrane. In Figure 2a (i), regarding the NMPC membrane, the representative bands and peaks have been described and explained in Section 3.1.1. In addition, Figure 2a (ii) shows the FTIR spectrum of the PVA membrane, in which the broad and strong band between 3500 and $3100 \mathrm{~cm}^{-1}$ was attributed to $\mathrm{O}-\mathrm{H}$ stretching from the intramolecular and intermolecular hydrogen bonds. The existence of peaks at $2942 \mathrm{~cm}^{-1}$ and $2910 \mathrm{~cm}^{-1}$ were attributed to the symmetric and antisymmetric stretching vibrations of $\mathrm{C}-\mathrm{H}$ from alkyl groups. Moreover, the peaks at $1721 \mathrm{~cm}^{-1}$ and $1656 \mathrm{~cm}^{-1}$ were related to $\mathrm{C}=\mathrm{O}$ stretching vibrations, while the peak at $1091 \mathrm{~cm}^{-1}$ was attributed to the $\mathrm{C}-\mathrm{O}$ stretching band, and these stretches were assigned to the remaining acetate groups during the production of PVA molecules from the hydrolysis of polyvinyl acetate [44-48]. The peak at $1558 \mathrm{~cm}^{-1}$ represented the $\mathrm{O}-\mathrm{H}$ bending vibration of hydroxyl groups [35], while the presence of sharp bands at 1415,1331 , and $844 \mathrm{~cm}^{-1}$ corresponded to $-\mathrm{CH}_{2},-\mathrm{CH}_{3}$, and $\mathrm{C}-\mathrm{H}$ bending, respectively.

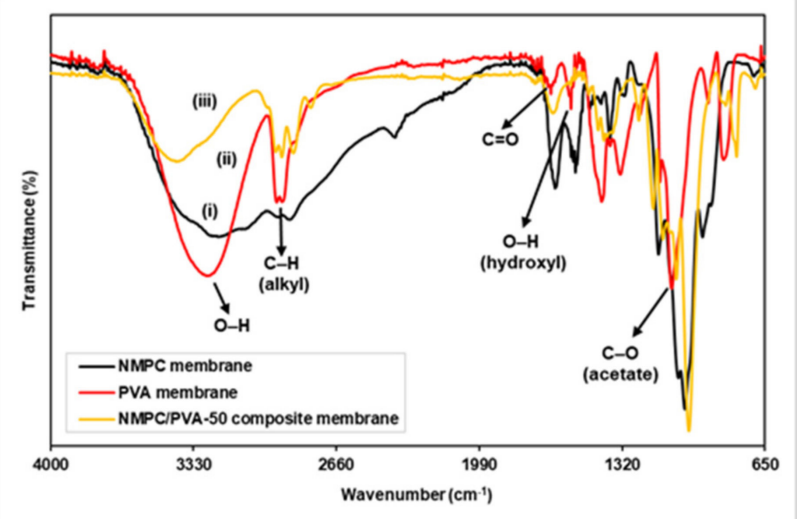

(a)

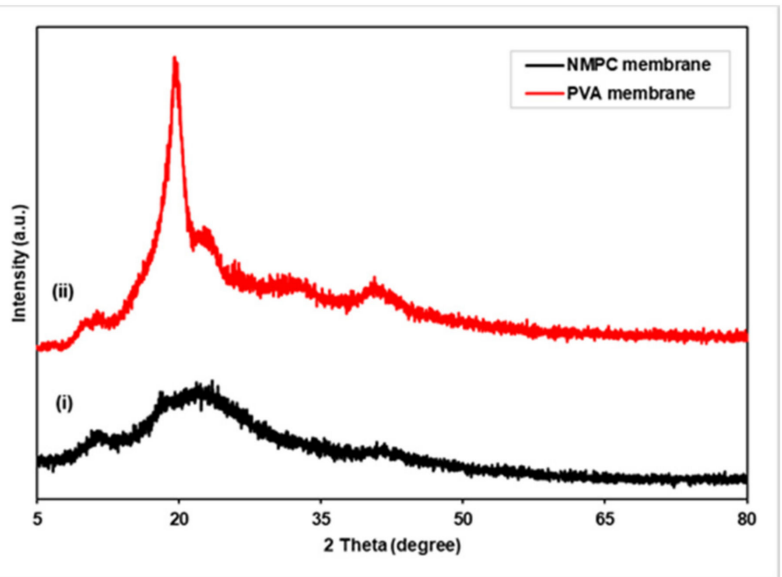

(c)

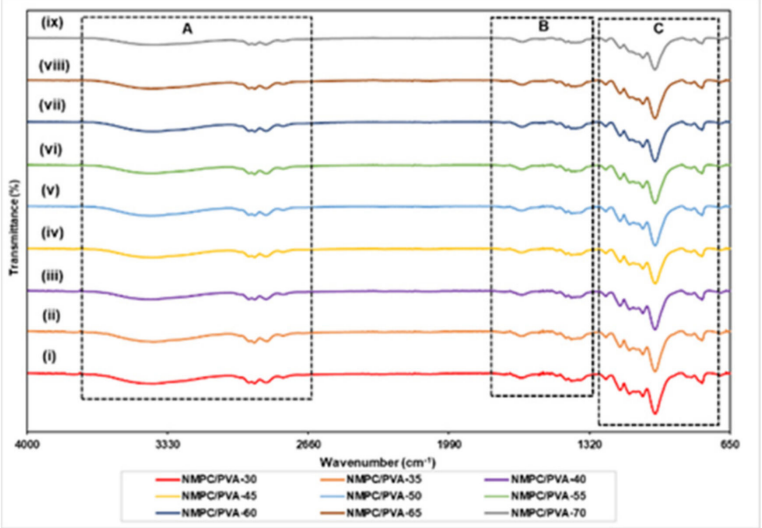

(b)

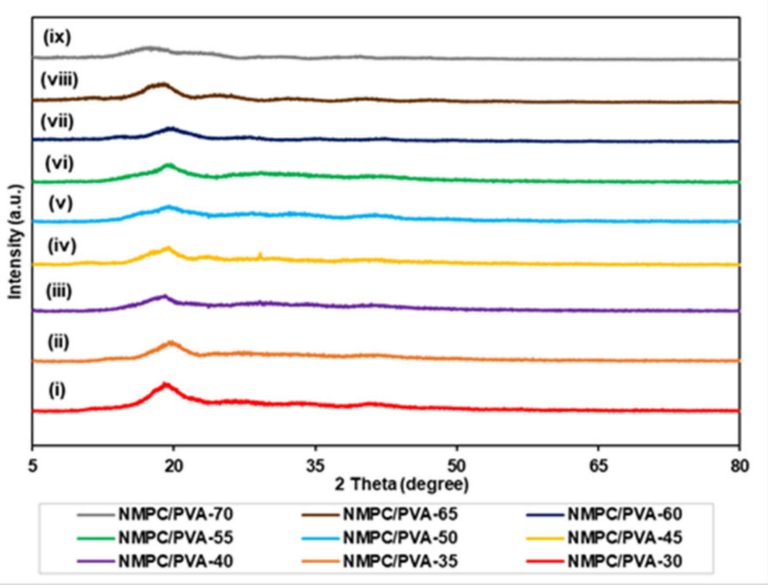

(d)

Figure 2. (a) FTIR spectra of NMPC membrane, PVA membrane, and NMPC/PVA-50 composite membrane, (b) FTIR spectra of NMPC/PVA composite membranes with different compositions, (c) XRD spectra of NMPC and PVA membrane, and (d) XRD spectra of NMPC/PVA composite membranes with different compositions. 
The FTIR spectra of NMPC/PVA composite membranes with different compositions are shown in Figure 2a (iii) as well as in Figure $2 b$ (i-ix). The broad band exhibited at $3405 \mathrm{~cm}^{-1}$ indicated N-H stretching, overlapping with $\mathrm{O}-\mathrm{H}$ stretching from both the NMPC and PVA molecules (Figure S2A). The intensity of this broad peak became weak when compared to unmodified NMPC and PVA membranes, which verified the formation of the NMPC/PVA composite membrane through hydrogen bonding between the NMPC segments and PVA chains (Figure 2a (iii)) [10,11]. The peaks at 2943, 2918, and $2862 \mathrm{~cm}^{-1}$ were assigned to C-H stretching (Figure S2A), whereas the peak at $1644 \mathrm{~cm}^{-1}$ indicated $\mathrm{N}-\mathrm{H}$ bending from the $-\mathrm{NH}_{3}{ }^{+}$groups of $\mathrm{NMPC}$ and overlapped with the $\mathrm{C}=\mathrm{O}$ stretching vibration (Figure S2B). Additionally, with an increasing NMPC content in the polymer matrix, the intensity of the peak for the absorption band at $1644 \mathrm{~cm}^{-1}$ increased. Moreover, the presence of peaks at 1476,1431, and $1394 \mathrm{~cm}^{-1}$ corresponded to $-\mathrm{CH}_{2}$ and $-\mathrm{CH}_{3}$ bending from the PVA segment and methylene of the NMPC molecule (Figure S2B). The peaks at $1132 \mathrm{~cm}^{-1}$ and $1062 \mathrm{~cm}^{-1}$ and the sharp peak with high intensity at $1006 \mathrm{~cm}^{-1}$ were ascribed to the $\mathrm{C}-\mathrm{O}$ stretching band, which overlapped with $\mathrm{P}-\mathrm{OH}$ stretching, while the peaks at $838 \mathrm{~cm}^{-1}$ and $782 \mathrm{~cm}^{-1}$ signified $\mathrm{C}-\mathrm{H}$ bending from both the PVA and NMPC molecules (Figure S2C).

XRD analyses were performed to confirm the change in the degree of crystallinity of unmodified NMPC and PVA membranes, as well as NMPC/PVA composite membranes. Figure $2 \mathrm{c}$ illustrates the XRD spectra of the unmodified NMPC and PVA membranes. The peaks at $2 \theta=11.40^{\circ}$ and $21.80^{\circ}$ showed that an amorphous structure existed in the NMPC polymer, with the amorphous percentage of $87.8 \%$ (Figure 2c (i)) [43]. Additionally, the PVA membrane showed a peak at $2 \theta=19.50^{\circ}$, which corresponded to the $\left(\begin{array}{lll}1 & 0 & 1\end{array}\right)$ plane, resulted from the semi-crystalline region of PVA with crystalline percentage of $47.2 \%$ and in contrast, the peak at $2 \theta=40.00^{\circ}$ was a broad band that indicated the amorphous region in the PVA polymer (Figure 2c (ii)) [49,50].

The peaks at $2 \theta=19.50^{\circ}$ for all NMPC/PVA composite membranes with different compositions exhibited the presence of amorphous regions in each membrane (Figure $2 \mathrm{~d}$ $(i-i x)$ ). The presence of a low intensity peak at $2 \theta=29.50^{\circ}$ of the NMPC/PVA- 45 composite membrane was likely due to the presence of impurities in the resulting membrane sample during the process of membrane production. XRD analysis showed that the crystallinity of the membranes decreased with an increasing NMPC content; hence, the amorphous region increased. The amorphous percentage of NMPC/PVA composite membranes increased with NMPC content of 30-50\%, with a percentage increase of 50.6-68.7\%, correlated with the increase of proton conductivity, while when the NMPC content increased up to 70\%, the amorphous percentage decreased to $55.7 \%$. The decrease in the crystallinity of membranes was due to the intermolecular interaction between both polymers that could destroy the hydrogen bonding between polymer chains and suppress the crystallinity. The decrease in crystallinity phase of membrane caused an increase in the movement of polymer chain segments, in turn aiding in the improvement of proton conductivity.

\subsubsection{Morphological Studies}

Figure S3a,b displayed the digital images of NMPC membrane and NMPC/PVA-50 composite membrane prepared in this work. Images were captured after drying the NMPC membrane and after cross-linking and drying process of the NMPC/PVA-50 composite membrane. Both images of NMPC-based membranes were yellowish in color (Figure S3a,b), whereas the NMPC/PVA-50 composite membrane exhibited an opaque and less flexible membrane with the addition of PVA (Figure S3b). Moreover, through physical observation and measurement of sample thickness using a thickness gauge, NMPC membrane has a lower thickness $(0.05 \mathrm{~mm})$ compared to NMPC/PVA composite membrane which has a thickness of around $0.10 \mathrm{~mm}$.

Changes in the morphology of the NMPC membrane, PVA membrane and NMPC/PVA composite membranes could be observed using FESEM (Figure 3). The FESEM micrographs in Figure 3 showed cross-sectional views of the NMPC membrane, PVA membrane, 
and NMPC/PVA composite membranes with different compositions, and the unmodified NMPC membrane displayed a dense, smooth, and homogeneous structure without obvious pores (Figure 3a). On the other hand, the PVA membrane displayed a porous and homogeneous structure (Figure $3 b$ ). Figure $3 c-k$ show that all composite membranes were homogeneously combined, and the structure of the composite membranes appeared fibrous with shallow pores. As shown in Figure $3 c-k$, the cross-sectional morphology has become rough when the NMPC polymer combined with the PVA polymer. Nevertheless, no phase separation occurred when combining both polymers, thus proving that they were compatible with each other when producing NMPC/PVA composite membranes.

Based on Figure $3 c-k$, the structures of all NMPC/PVA composite membranes exhibited porous structures due to the presence of PVA, which has hydrophilic properties and excellent water permeability. The structure of a membrane plays an important role in controlling these factors because porous structures exhibit high flux or water permeability and low selectivity, while dense structures show the opposite. The NMPC/PVA composite membrane showed porous morphology due to the cross-linking process that occurred with all composite membranes [51].
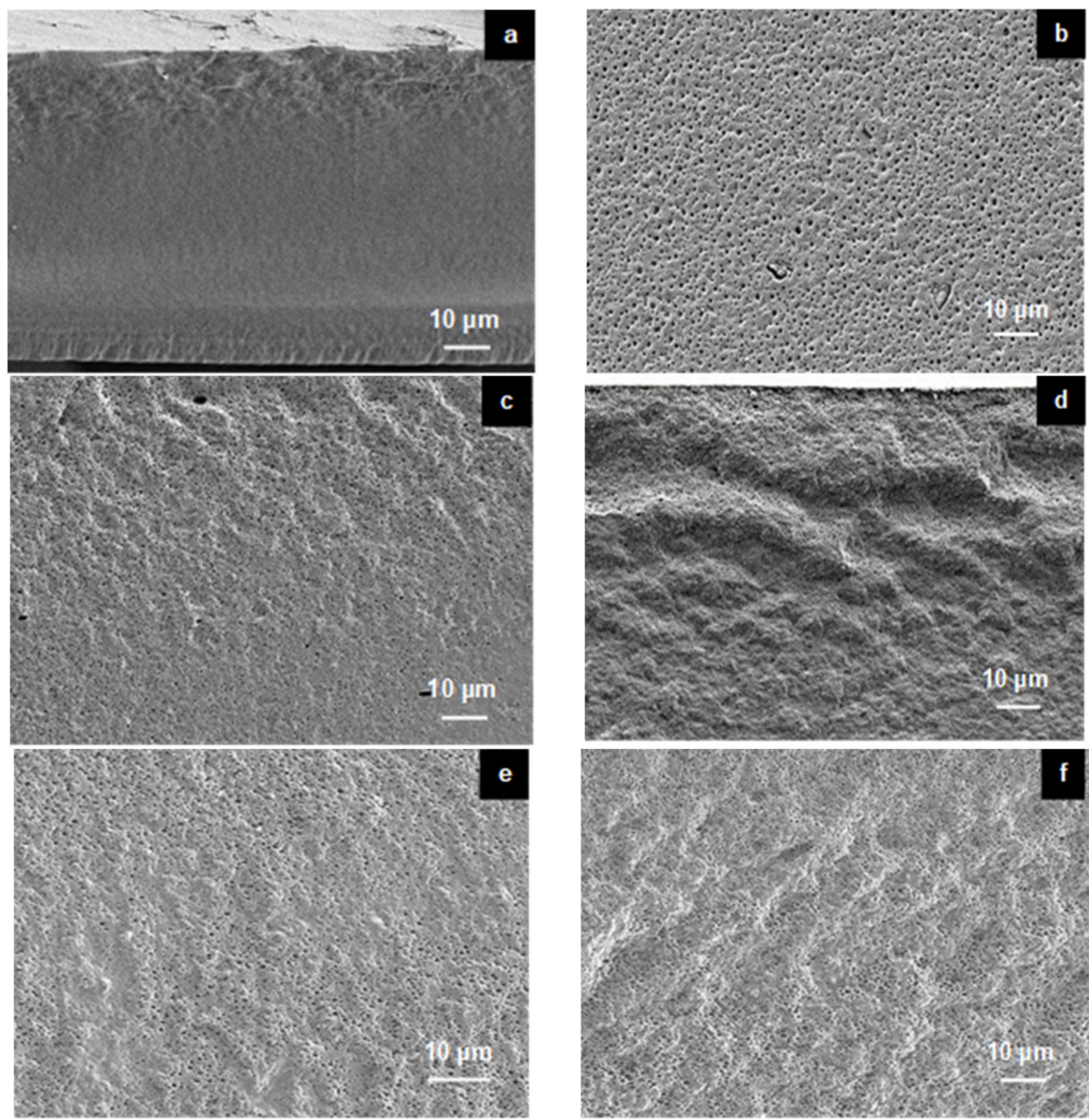

Figure 3. Cont. 


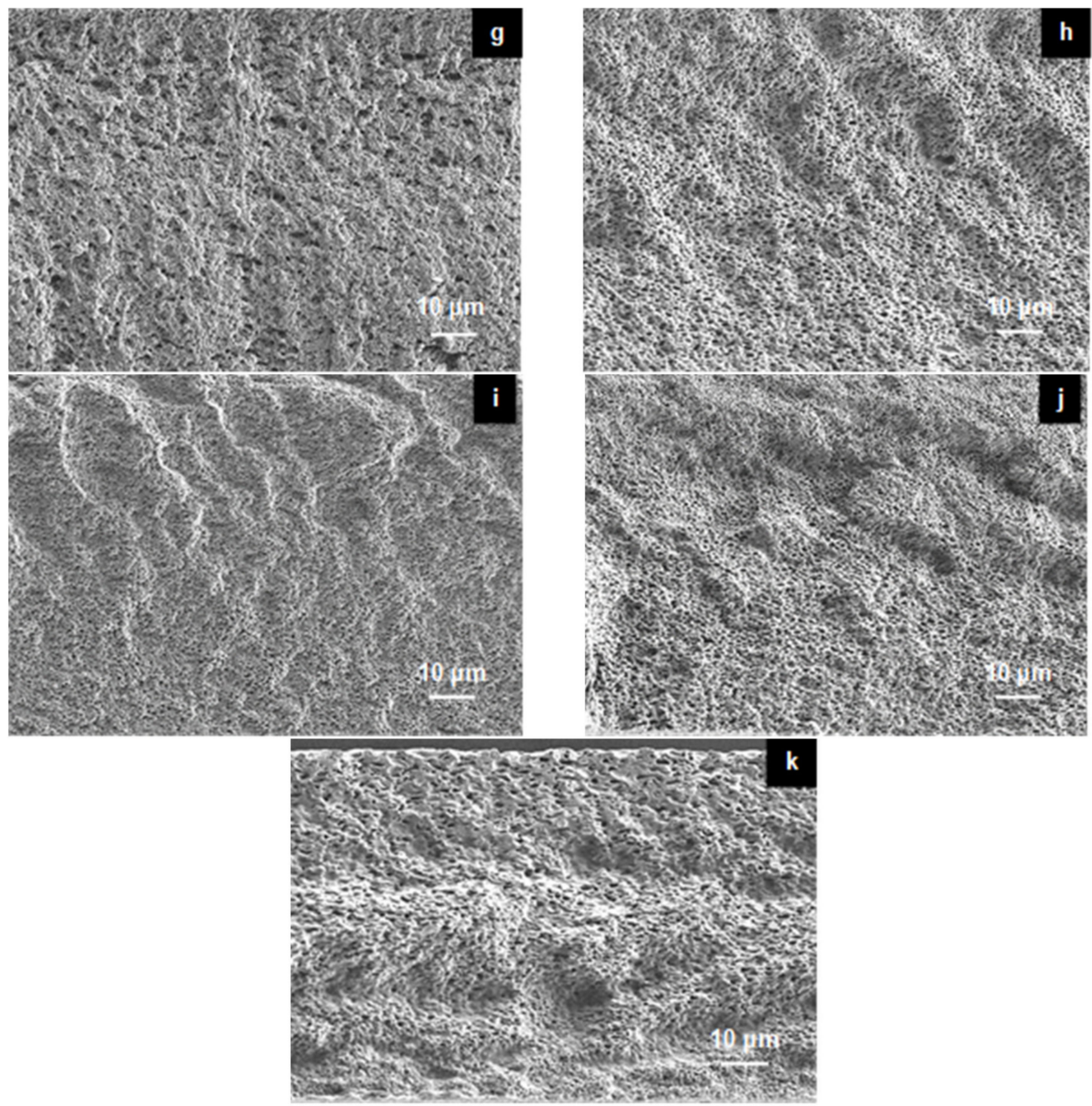

Figure 3. FESEM micrographs of the cross-sectional views for the (a) NMPC membrane, (b) PVA membrane, (c) NMPC/PVA-30 membrane, (d) NMPC/PVA-35 membrane, (e) NMPC/PVA-40 membrane, (f) NMPC/PVA-45 membrane, (g) NMPC/PVA-50 membrane, (h) NMPC/PVA-55 membrane, (i) NMPC/PVA-60 membrane, (j) NMPC/PVA-65 membrane, and (k) NMPC/PVA-70 membrane.

\subsubsection{Thermal Stability}

Thermogravimetric analysis (TGA) was carried out to determine the thermal stability of the NMPC membrane and NMPC/PVA composite membranes. The TGA curve of the NMPC membrane in Figure 4 showed two stages of weight loss. The first stage of weight loss was approximately $17 \%$ over the temperature of $70^{\circ} \mathrm{C}$, which was attributed to the loss of the moisture content in the membrane as well as the elimination of side groups. The second stage of weight loss occurred at approximately $200{ }^{\circ} \mathrm{C}$ with a weight loss of approximately $40 \%$ because the decomposition of functional groups existed in NMPC biopolymer $\left(\mathrm{CH}_{2}, \mathrm{NH}_{2}\right.$, and $\left.\mathrm{PO}_{3} \mathrm{H}\right)$. 


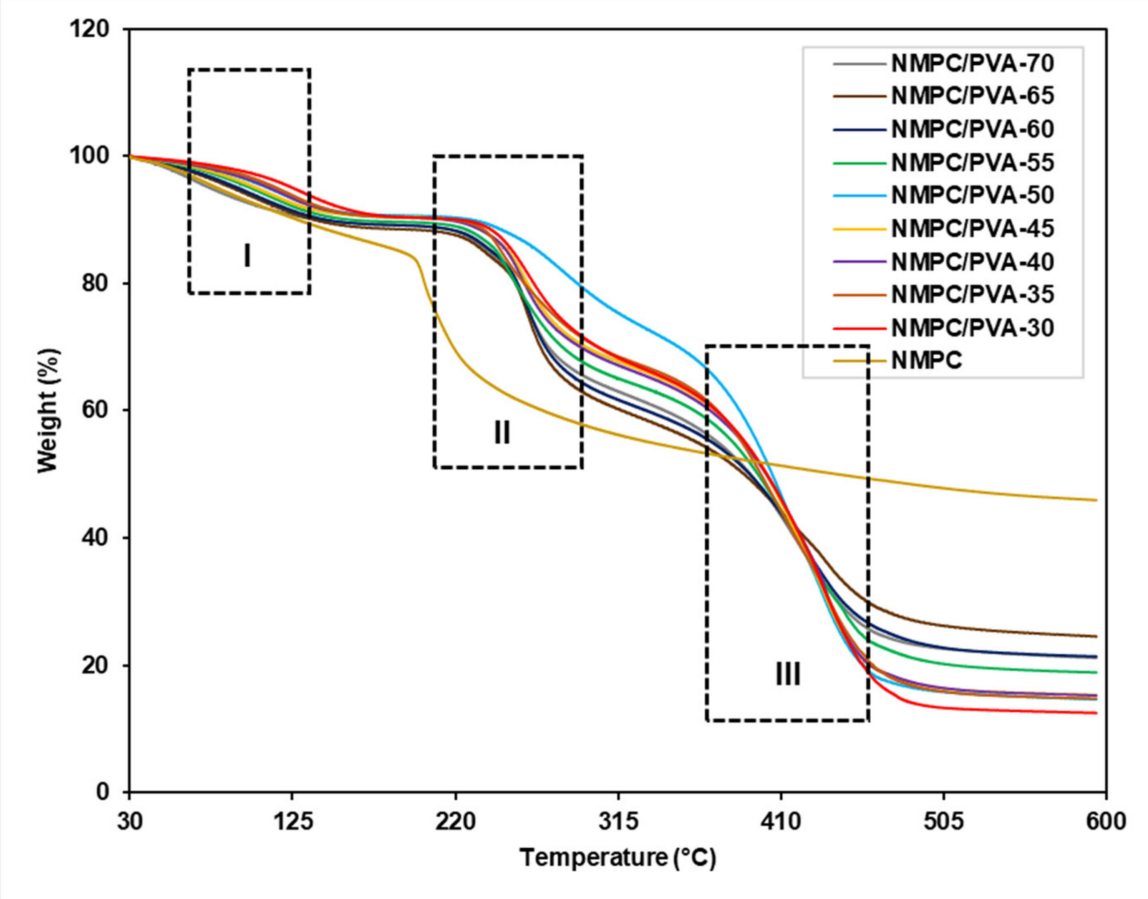

Figure 4. TGA curves of the NMPC membrane and NMPC/PVA composite membranes with different compositions.

In contrast, the TGA curves presented in Figure 4 show that all prepared NMPC/PVA composite membranes followed similar degradation behavior. There were three stages of degradation that occurred in the NMPC/PVA composite membranes as shown in Figure 4 (I, II, and III). The first stage of degradation occurred from approximately $80-100{ }^{\circ} \mathrm{C}$, with a weight loss of approximately $9-10 \%$ that was due to the loss of absorbed water molecules in the membrane matrix. The second weight loss was in the range of $230-300{ }^{\circ} \mathrm{C}$, which was ascribed to the loss of PVA polymer and the thermal degradation of the crosslinking network formed in the membrane matrix. The second stage weight loss occurred at around $230{ }^{\circ} \mathrm{C}$ indicated that there was an increase in the thermal stability of this modified biopolymer due to the cross-linking that occurred in the membrane [10]. The third stage of degradation was due to the decomposition of the main polymer chain in the membrane from approximately $370-460{ }^{\circ} \mathrm{C}$ with a weight loss of approximately $37-54 \%$. Table S1 exhibited the thermal stability analysis of NMPC membrane and NMPC/PVA composite membranes with different compositions according to the three degradation stages and weight losses (I, II, and III), as labelled in Figure 4. The thermal stability of the NMPC/PVA composite membranes slightly improved when compared to the unmodified NMPC membrane because of the hydrogen bond interaction between the NMPC and PVA polymers. Throughout this study, it could be concluded that the NMPC/PVA-65 composite membrane showed the highest thermal stability among the other membranes. The improvement in the thermal stability of the NMPC/PVA-65 composite membrane was due to its higher residual content (approximately 25\%) compared to the NMPC/PVA composite membrane with other ratios (13-22\%). However, there are some factors that could be considered to affect the thermal stability of the NMPC/PVA-70 composite membrane, which demonstrated less residual content, including the crystallinity of the membrane and degree of cross-linking that has not been determined in this study.

\subsubsection{DMA Analysis}

Dynamic mechanical analysis (DMA) is a sensitive technique that yields information on bulk properties and thermal transitions, as well as other minor phase or structural changes of polymers [52]. The dynamic mechanical properties were demonstrated by 
the $\tan \delta$, storage modulus, and loss modulus. The tan $\delta$ and loss modulus peaks were described as the glass transition temperature, where the tan $\delta$ peak occurred at a higher temperature than the loss modulus [53]. Tan $\delta$ is known as a good limit of the leather-like midpoint between the glassy and rubbery states, whereas the storage modulus is a limit of the recoverable stored strain energy, while the loss modulus is a limit of the energy consumed, which is lost as heat [52,54].

Figure $5 \mathrm{a}-\mathrm{i}$ shows the changes in $\tan \delta$ and storage modulus versus temperature for the NMPC/PVA composite membranes with different compositions, whereas Figure S4 shows the comparisons of tan $\delta$ curves for all NMPC/PVA composite membranes. The sharp peaks presented on the $\tan \delta$ curves represented $\mathrm{T}_{\mathrm{g}}$ and the plot on the storage modulus was a transition corresponding to the presence of peak at $\tan \delta$. As the process was moving from a very low temperature, the molecules of the composite membranes were tightly compressed to higher temperatures. The molecules were expanded, and the free volume increased, allowing side chain movement to occur; this behavior is known as a beta transition $\left(T_{\beta}\right)$, which was often related to toughness. The glass transition $\left(T_{g}\right)$, which only occurred in the amorphous materials, appeared as the heating process continued, and the chains in the amorphous regions began to coordinate into large-scale chains; thus, the amorphous region started to melt into a rubbery phase $[55,56]$. Based on Figure $5 a-i$ and Figure S4, on the tan $\delta$ curve, it can be observed that $\mathrm{T}_{\mathrm{g}}$ occurred between 118 and $130{ }^{\circ} \mathrm{C}$ for all composite membranes. In addition, the range of $\mathrm{T}_{\mathrm{g}}$ peak heights for all composite membranes was $0.3-0.6$ and could be seen on the tan $\delta$ curve. This $\mathrm{T}_{\mathrm{g}}$ value represented the amorphous phase in the membrane and could be zero for samples that were in fully crystalline phase [55]. Figure $5 \mathrm{~h}-\mathrm{i}$ shows that the $\mathrm{T}_{\mathrm{g}}$ peak value on $\tan \delta$ curve (around 0.3 ) for NMPC/PVA-65 and NMPC /PVA-70 composite membranes experienced a decrease in the amorphous phase, corresponded to the decrease in amorphous percentage discussed in the XRD analysis (Section 3.2.1). According to the graphs, another peak might exist at temperatures below $35^{\circ} \mathrm{C}$, although the data did not include sufficiently low temperatures to fully capture this peak [52].

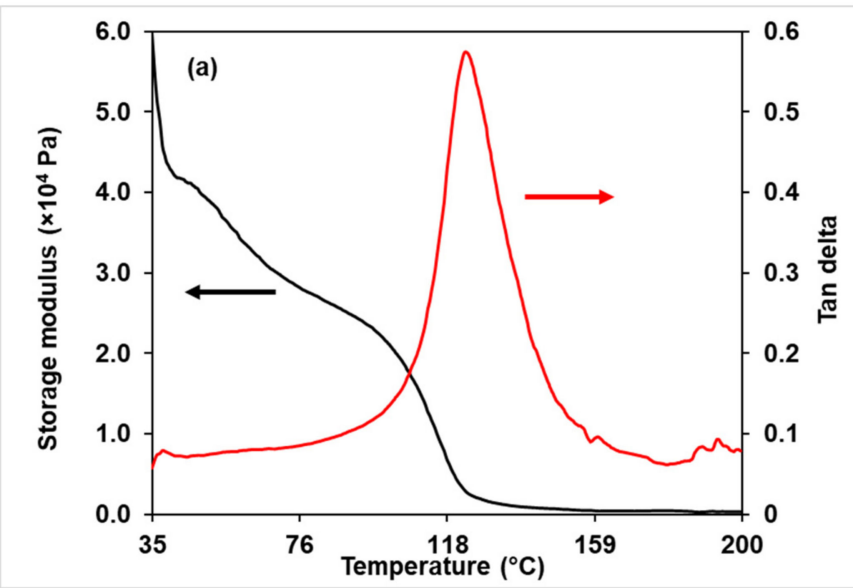

(a)

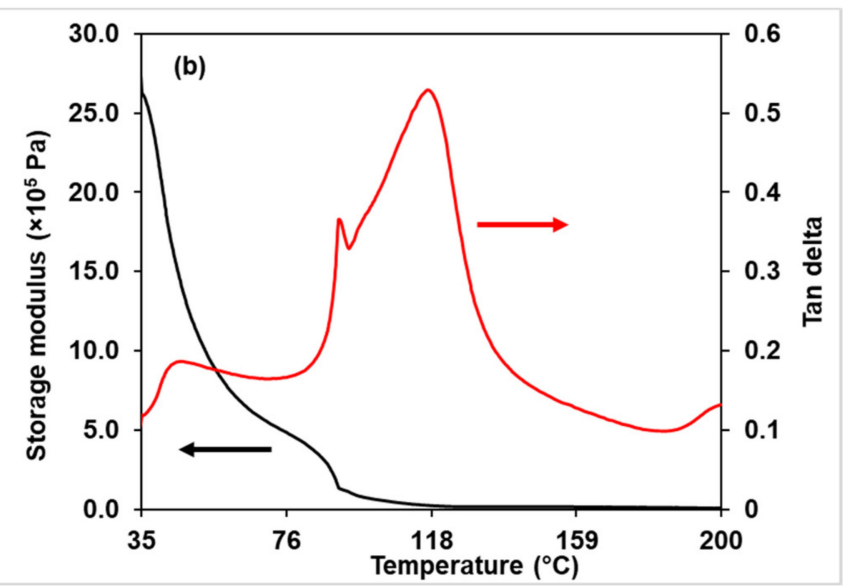

(b)

Figure 5. Cont. 


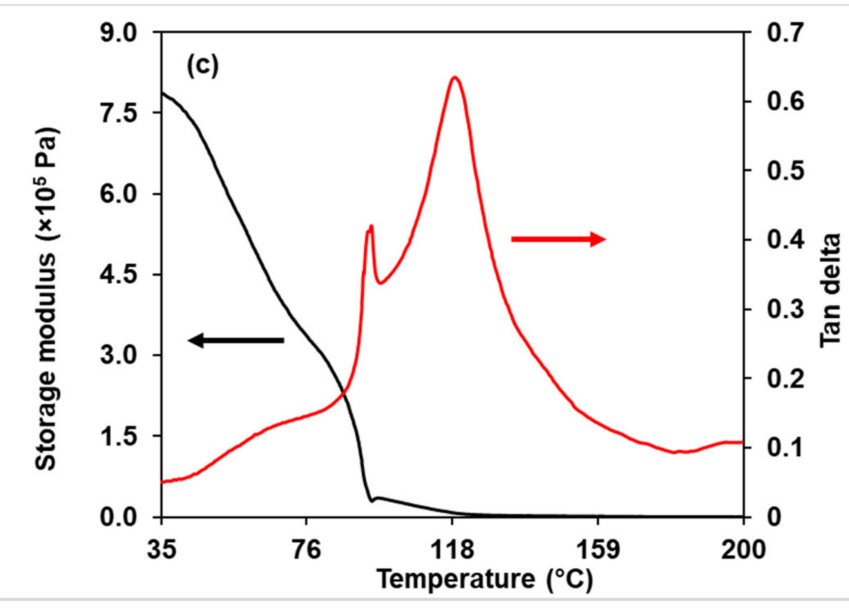

(c)

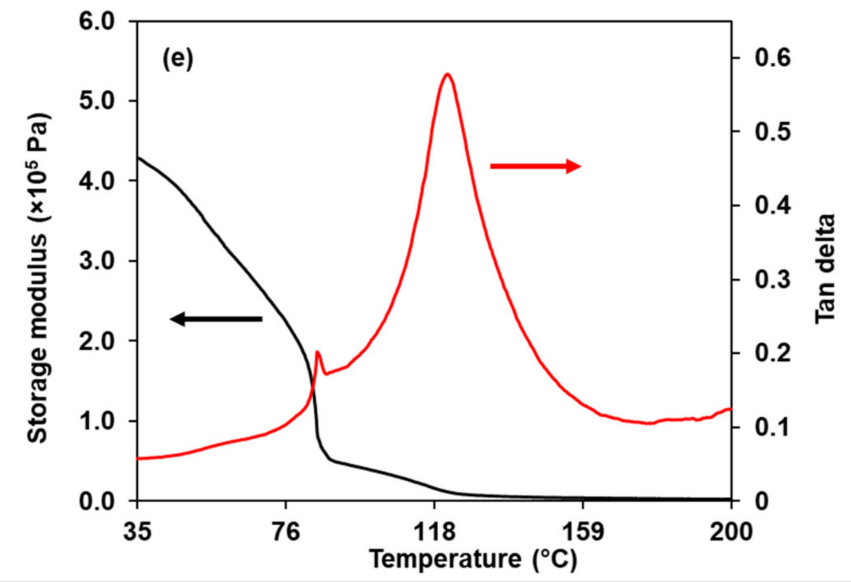

(e)

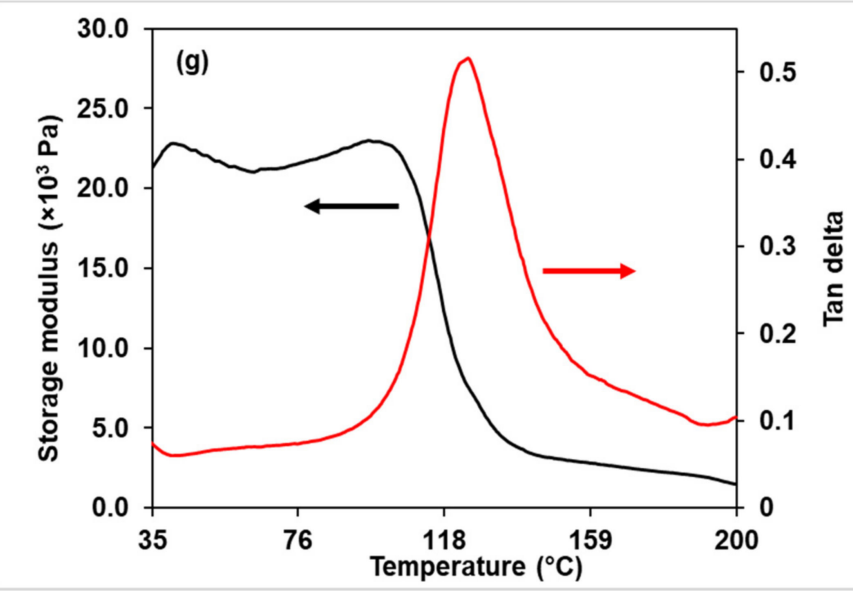

(g)

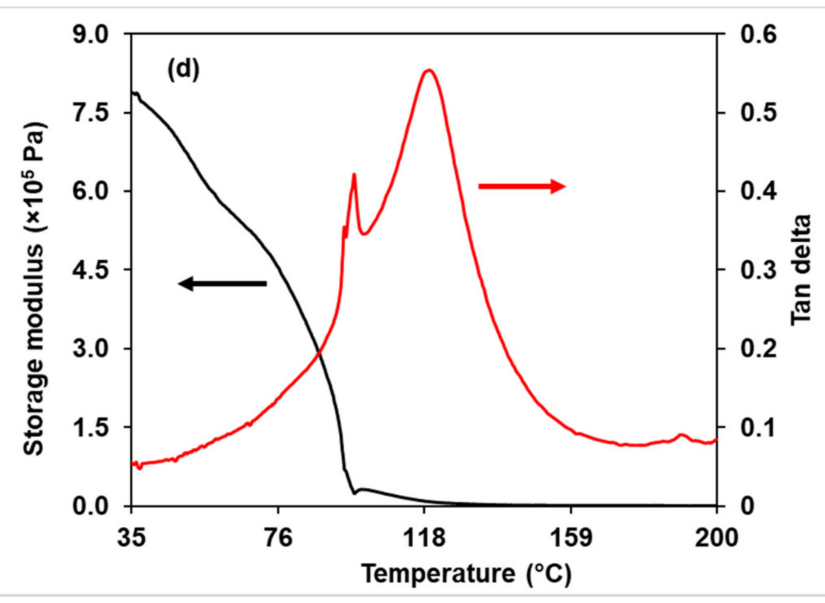

(d)

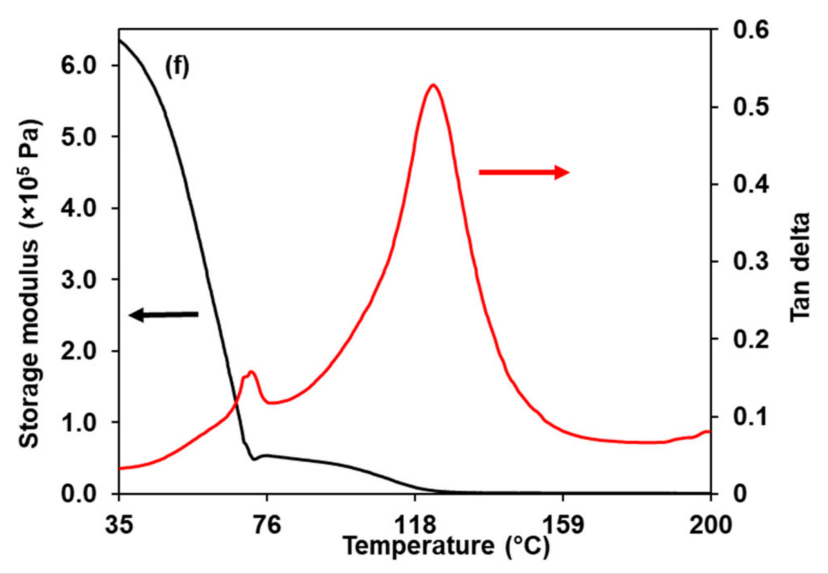

(f)

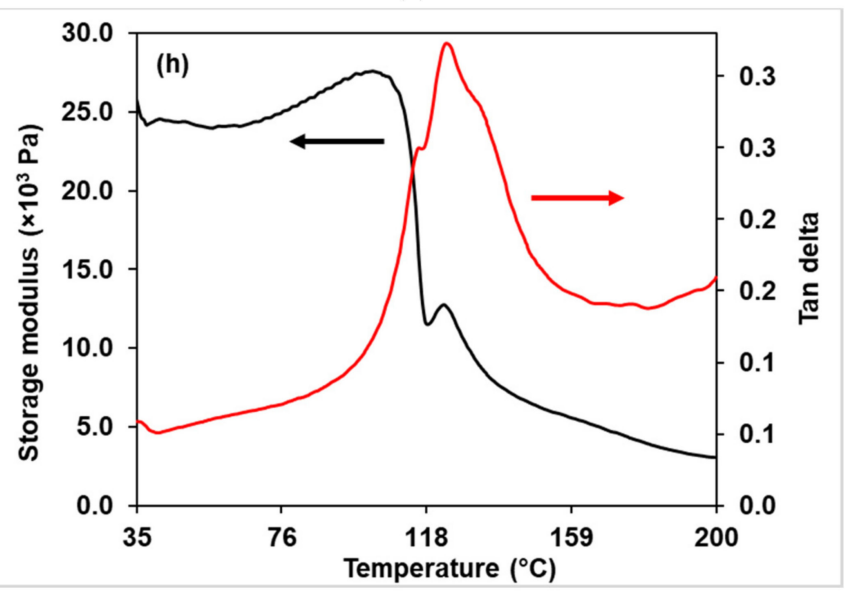

(h)

Figure 5. Cont. 


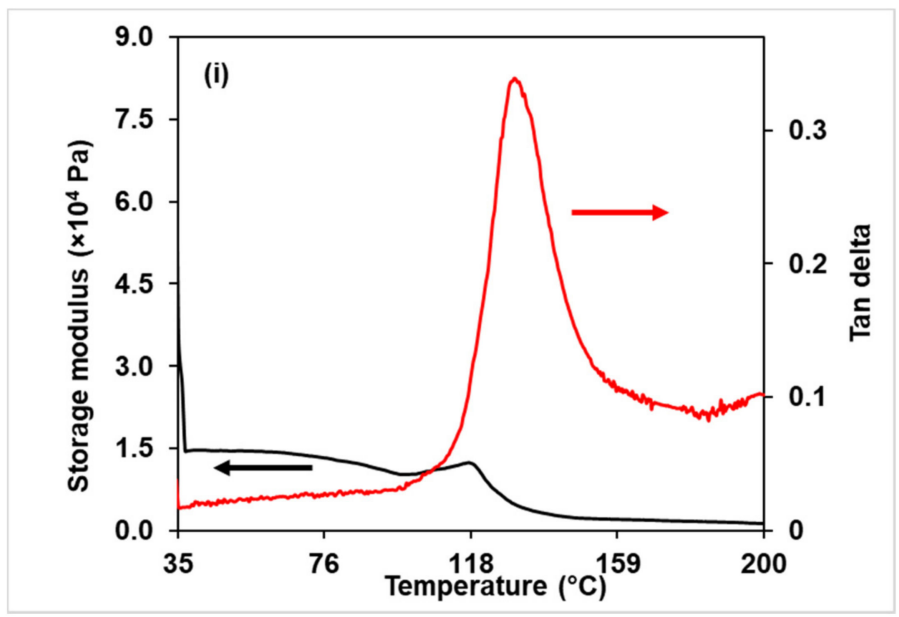

(i)

Figure 5. Tan $\delta$ and storage modulus of (a) NMPC/PVA-30 membrane, (b) NMPC/PVA-35 membrane, (c) NMPC/PVA-40 membrane, (d) NMPC/PVA-45 membrane, (e) NMPC/PVA-50 membrane, (f) NMPC/PVA-55 membrane, (g) NMPC/PVA60 membrane, (h) NMPC/PVA-65 membrane, and (i) NMPC/PVA-70 membrane.

The storage modulus for all NMPC/PVA composite membranes is shown in Figure 5a-i, in which the trend was quite inconsistent. The inconsistency of this trend might be contributed by the thickness and degree of cross-linking of the composite membranes. As the NMPC content increased to $35 \%$ (Figure $5 b)$, the storage modulus increased $\left(2.46 \times 10^{6} \mathrm{~Pa}\right)$ and then decreased slightly as the NMPC content further increased. Furthermore, the storage modulus value decreased as 70\% NMPC content (Figure 5i) was added to the membrane. The storage modulus values for the composite membranes with NMPC contents of $30-55 \%$ experienced a decrease when the temperature increased to around $100{ }^{\circ} \mathrm{C}$. The NMPC/PVA composite membranes with 60-70\% NMPC content (Figure 5g-i) exhibited a storage modulus peak or hump directly at the edge of the preceding drop that correlated to the $T_{g}$. This peak or hump referred to the overshoot at $T_{g}$, which was caused by stress relief. The stress was trapped in the membrane matrix until enough movement was attained at the $T_{g}$ to induce the movement of chains to a lower energy state [57]. Additionally, the storage modulus of the initial value (at a temperature of around $35^{\circ} \mathrm{C}$ ) was maintained at approximately $100^{\circ} \mathrm{C}$ in the NMPC/PVA composite membranes with NMPC content of $60-70 \%$ (Figure $5 \mathrm{~g}-\mathrm{i}$ ). The retention of these storage modulus values demonstrated the mechanical stability of the composite membrane at higher temperature, making it potentially applicable for fuel cell applications.

\subsubsection{Water Uptake, Swelling Ratio, Ion Exchange Capacity, and Proton Conductivity}

The proton conductivity of membranes was closely related to the water uptake values through the hydration degree. Proton conductivity could be promoted as hydrogen bond networks formed between the membrane and water molecules under hydrated conditions. In this study, the water uptake, swelling area, and swelling thickness of composite membranes at room temperature were measured and are presented in Table 1. As expected, pure, unmodified NMPC had a high degree of hydrophilicity, as it dissolved immediately when it was immersed in water or acetic acid; hence, its water uptake and swelling ratio could not be measured. Regarding the NMPC/PVA composite membranes, the water uptake increased with an increasing NMPC content in the membrane matrix $(32.1 \%-51.9 \%)$ and then slightly decreased at some point. The highest water uptake (51.9\%) was observed in the same ratio content of NMPC and PVA (NMPC/PVA-50). The reason for this increase was due to the presence of hydrophilic groups $\left(-\mathrm{NH}_{2}\right.$ and $\left.-\mathrm{OH}\right)$ in NMPC and PVA, which helped to attract water. 
Table 1. Thickness, water uptake, swelling area, swelling thickness, IEC, and proton conductivity of the NMPC/PVA composite membranes with different compositions.

\begin{tabular}{ccccccc}
\hline $\begin{array}{c}\text { Membrane } \\
\text { Sample }\end{array}$ & $\begin{array}{c}\text { Thickness } \\
(\mathbf{m m})\end{array}$ & $\begin{array}{c}\text { Water } \\
\text { Uptake (\%) }\end{array}$ & $\begin{array}{c}\text { Swelling } \\
\text { Area (\%) }\end{array}$ & $\begin{array}{c}\text { Swelling } \\
\text { Thickness (\%) }\end{array}$ & $\begin{array}{c}\text { IEC } \\
\text { (mequiv } \mathbf{g}^{-\mathbf{1})}\end{array}$ & $\begin{array}{c}\text { Proton Conductivity } \\
\mathbf{( 1 0}^{-\mathbf{5}} \mathbf{S ~ c m}^{-\mathbf{1}} \mathbf{)}\end{array}$ \\
\hline NMPC/PVA-30 & $0.06 \pm 0.02$ & $32.1 \pm 5.2$ & $15.1 \pm 3.6$ & $46.5 \pm 5.9$ & $0.24 \pm 0.08$ & $2.61 \pm 0.29$ \\
NMPC/PVA-35 & $0.07 \pm 0.03$ & $37.3 \pm 5.1$ & $25.4 \pm 7.1$ & $51.2 \pm 5.3$ & $0.39 \pm 0.02$ & $3.45 \pm 0.38$ \\
NMPC/PVA-40 & $0.08 \pm 0.01$ & $44.4 \pm 2.3$ & $29.6 \pm 16.3$ & $58.6 \pm 5.9$ & $0.40 \pm 0.03$ & $4.96 \pm 0.33$ \\
NMPC/PVA-45 & $0.08 \pm 0.02$ & $48.4 \pm 3.5$ & $33.4 \pm 7.1$ & $61.3 \pm 1.6$ & $0.42 \pm 0.06$ & $6.59 \pm 0.19$ \\
NMPC/PVA-50 & $0.09 \pm 0.01$ & $51.9 \pm 2.3$ & $35.1 \pm 16.3$ & $62.2 \pm 3.3$ & $0.45 \pm 0.02$ & $8.76 \pm 0.16$ \\
NMPC/PVA-55 & $0.10 \pm 0.02$ & $49.5 \pm 5.5$ & $33.3 \pm 12.9$ & $54.3 \pm 2.3$ & $0.38 \pm 0.04$ & $7.47 \pm 0.25$ \\
NMPC/PVA-60 & $0.10 \pm 0.04$ & $48.3 \pm 6.5$ & $30.7 \pm 7.8$ & $51.2 \pm 2.8$ & $0.36 \pm 0.03$ & $5.38 \pm 0.41$ \\
NMPC/PVA-65 & $0.11 \pm 0.01$ & $42.5 \pm 6.2$ & $24.1 \pm 5.1$ & $45.1 \pm 2.2$ & $0.33 \pm 0.02$ & $4.26 \pm 0.34$ \\
NMPC/PVA-70 & $0.12 \pm 0.03$ & $39.1 \pm 2.9$ & $17.8 \pm 9.8$ & $39.2 \pm 1.9$ & $0.29 \pm 0.07$ & $3.59 \pm 0.46$ \\
\hline
\end{tabular}

The swelling ratios, which were the swelling area and swelling thickness of all NMPC/PVA composite membranes, are also shown in Table 1. Generally, a higher water uptake can induce a higher swelling ratio. Table 1 shows that both the swelling area and swelling thickness increased with increasing water uptake values and slightly decreased when the percentage of water uptake decreased; all the composite membranes exhibited similar trends. Additionally, all NMPC/PVA composite membranes underwent a crosslinking process. Ionic cross-linking might not be sufficient to depress the swelling of composite membranes; however, the covalent cross-linking that occurred in the membrane matrix could inhibit the dissolution and excess swelling of the composite membranes [10].

The IEC represented the number of active sites or functional groups that were responsible for ion exchange in the polymer electrolyte membranes and was also related to proton conduction for the composite membranes. The IEC values for the NMPC/PVA composite membranes with different compositions are presented in Table 1. The increase in NMPC content (30-50\%) in the NMPC/PVA composite membranes increased the IEC magnitude from 0.24 to 0.45 mequiv $\mathrm{g}^{-1}$ and decreased $\left(0.38-0.29\right.$ mequiv $^{-1}$ ) to some extent when the NMPC content was further increased (55-70\%). Based on the IEC values shown, it can be concluded that the increase in density of $-\mathrm{PO}_{3} \mathrm{H}_{2}$ groups contributed to the improvement in IEC, which was predicted to enhance the proton conductivity of the NMPC/PVA composite membranes [10]. However, as the content of NMPC exceeded $50 \mathrm{wt} . \%$, the IEC values experienced decrement, which might be due to the degree of cross-linking of membranes that has not been determined and the decrease in percentage of amorphous region, hence the conductivity values were also expected to be decreased.

Proton conductivity is a significant feature of fuel cell membranes, as the efficiency of fuel cell performance depends on proton conductivity. Figure S5 shows the typical Nyquist plots, with semicircles at lower frequencies and the linear diffusion impedance on the $x$-axis, which represented the bulk resistance $\left(R_{b}\right)$ of the membrane matrix. The proton conductivity of the NMPC/PVA composite membranes with different compositions was measured at room temperature under hydrated conditions and is shown in Table 1 . The proton conductivity of the pure, unmodified NMPC membrane was measured under dry condition, as it could not be immersed in water due to its dissolution effect and low proton conductivity $\left(2.74 \times 10^{-6} \mathrm{~S} \mathrm{~cm}^{-1}\right)$. Additionally, in the NMPC/PVA composite membranes, the proton conductivity increased with an increasing NMPC content in the membrane matrix from $30-50 \%$, with values of $2.61 \times 10^{-5}-8.76 \times 10^{-5} \mathrm{~S} \mathrm{~cm}^{-1}$, respectively, and then decreased as the NMPC content was further increased. The increase in proton conductivity of the composite membranes might be due to the presence of zwitterionic architecture (Figure 6), which gave rise to hydrophilic regions in the membrane matrix because of its strong affinity toward water. These hydrophilic regions promoted the absorption of water and facilitated proton transport, and with the increase in NMPC content in the membrane matrix, protons existed in the form of $\mathrm{H}_{3} \mathrm{O}^{+}$passing through the hydrophilic regions and increasing the proton conductivity [10]. This increase in proton conductivity was correlated 
with the increase in water uptake and the IEC, which synchronized with the increase in hydrophilic groups in the NMPC/PVA composite membranes. Proton transport in the membrane is known and can be described by two mechanisms: vehicle and Grotthuss (hopping) mechanisms. The bound water in the membrane was probably associated with the Grotthuss mechanism, while the free water in the membrane participated in the vehicle mechanism, proving that the presence of water was vital for proton conduction in the membrane $[58,59]$.
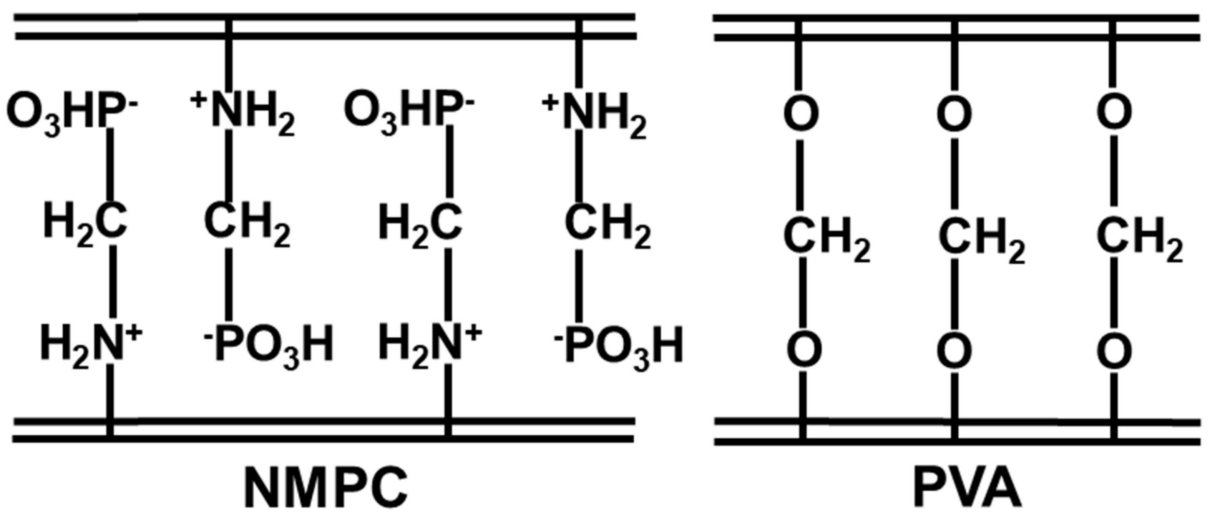

Figure 6. Schematic of zwitterionic structure in NMPC/PVA composite membrane.

3.3. N-Methylene Phosphonic Chitosan/Poly (Vinyl Alcohol) Composite Membranes Modified with $\mathrm{SiO}_{2}$ Filler (NMPC/PVA-SiO ${ }_{2}$ )

3.3.1. FTIR and XRD Analysis

FTIR analysis was one of the most important characterizations and was performed to identify the chemical structures present in the filler and produced composite membranes. Figure 7a shows the FTIR spectra for $\mathrm{SiO}_{2}$, the NMPC/PVA-50 composite membrane and the NMPC/PVA-SiO 2 (4 wt.\%) composite membrane. The FTIR spectra of the $\mathrm{SiO}_{2}$ filler (Figure $7 \mathrm{a}$ (i)) exhibited a band at $3348 \mathrm{~cm}^{-1}$, which was associated with the $\mathrm{O}-\mathrm{H}$ stretching vibration of absorbed water molecules, and the peak at $1654 \mathrm{~cm}^{-1}$ was the bending vibration of these water molecules. The absorption band at $1057 \mathrm{~cm}^{-1}$ corresponded to the asymmetric stretching mode for the vibration of $\mathrm{Si}-\mathrm{O}-\mathrm{Si}$ bonds in the $\mathrm{SiO}_{2}{ }^{4-}$ four-coordinate species $\left(\mathrm{Si}-(\mathrm{SiO})^{4}=\mathrm{Q}^{4}\right)$ in the oxide phase on the surface, which was a typical band for the pure and amorphous $\mathrm{SiO}_{2}$ fillers [60]. The broad band in the $3800-2500 \mathrm{~cm}^{-1}$ region represented hydrogen bonds from the different $\mathrm{O}-\mathrm{H}$ groups present in $\mathrm{SiO}_{2}$. Moreover, the region at $1200-770 \mathrm{~cm}^{-1}$ showed that $\mathrm{SiO}_{2}$ had specific bands focused on the $\mathrm{Si}-\mathrm{O}-\mathrm{Si}, \mathrm{Si}-\mathrm{O}$, and $\mathrm{Si}-\mathrm{OH}$ stretching vibrations, and the peak at $796 \mathrm{~cm}^{-1}$ referred to the vibration mode of $\mathrm{O}-\mathrm{Si}-\mathrm{O}$ from $\mathrm{SiO}_{2}$ crystals [61-63].

The representative FTIR peaks and bands of NMPC/PVA membranes (Figure 7a (ii)) have been explained in Section 3.2.1. The FTIR spectra of the $\mathrm{NMPC} / \mathrm{PVA}-\mathrm{SiO}_{2} \mathrm{Composite}$ membranes are shown in Figure $7 \mathrm{a}$ (iii), as well as in Figure $7 \mathrm{~b}$ (i-vii), with different compositions of $\mathrm{SiO}_{2}$ fillers. The NMPC/PVA-SiO 2 composite membrane showed no significant change in the FTIR spectrum compared to the unmodified NMPC/PVA composite membrane, and the main vibration spectra presented were quite similar. The broad band exhibited at $3405 \mathrm{~cm}^{-1}$ showed $\mathrm{N}-\mathrm{H}$ stretching, overlapping with the $\mathrm{O}-\mathrm{H}$ stretching from the NMPC, PVA, and $\mathrm{SiO}_{2}$ molecules (Figure S6A). This broad peak intensity became weak when compared to the NMPC/PVA composite membranes, confirming the formation of NMPC/PVA-SiO 2 composite membranes through hydrogen bonding between the NMPC segments, PVA chains, and $\mathrm{SiO}_{2}$ segments. The peaks at 2943, 2915, and $2862 \mathrm{~cm}^{-1}$ were associated with C-H stretching (Figure S6A). The peak at $1645 \mathrm{~cm}^{-1}$ shifted to a lower frequency of $1639 \mathrm{~cm}^{-1}$ and was attributed to the $\mathrm{N}-\mathrm{H}$ bending from the $-\mathrm{NH}_{3}{ }^{+}$group in $\mathrm{NMPC}$, overlapping with the $\mathrm{C}=\mathrm{O}$ stretching vibration and bending vibration of water molecules from the $\mathrm{SiO}_{2}$ segment (Figure S6B). The peaks at 1476,1432 , and $1406 \mathrm{~cm}^{-1}$ cor- 
responded to the $-\mathrm{CH}_{2}$ and $-\mathrm{CH}_{3}$ bending of the PVA segment and methylene phosphonic group in the NMPC molecule (Figure S6B). The peaks at $1129 \mathrm{~cm}^{-1}$ and $1065 \mathrm{~cm}^{-1}$ and the sharp peak with high intensity at $1007 \mathrm{~cm}^{-1}$ were attributed to the C-O stretching bands, which overlapped with the $\mathrm{P}-\mathrm{OH}$ stretching from the NMPC molecule and can be seen in Figure S6C. The peak at $1065 \mathrm{~cm}^{-1}$ shifted to a lower frequency of $1055 \mathrm{~cm}^{-1}$ due to Si-O-Si stretching and Si-OH stretching at $1007 \mathrm{~cm}^{-1}$ of the $\mathrm{SiO}_{2}$ molecules in that region. In addition, the peaks at $834 \mathrm{~cm}^{-1}$ and $783 \mathrm{~cm}^{-1}$ indicated that the $\mathrm{C}-\mathrm{H}$ bending from both the PVA and NMPC molecules overlapped with the Si-O-Si stretching and O-Si-O vibration of the $\mathrm{SiO}_{2}$ molecules (Figure $\mathrm{S} 6 \mathrm{C}$ ).

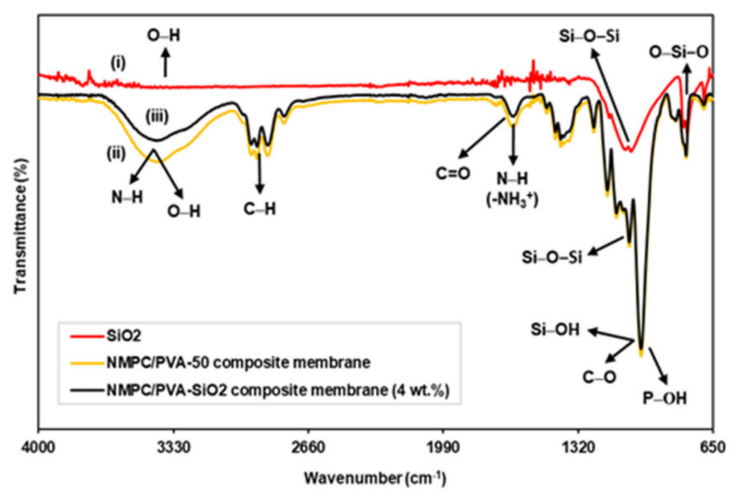

(a)

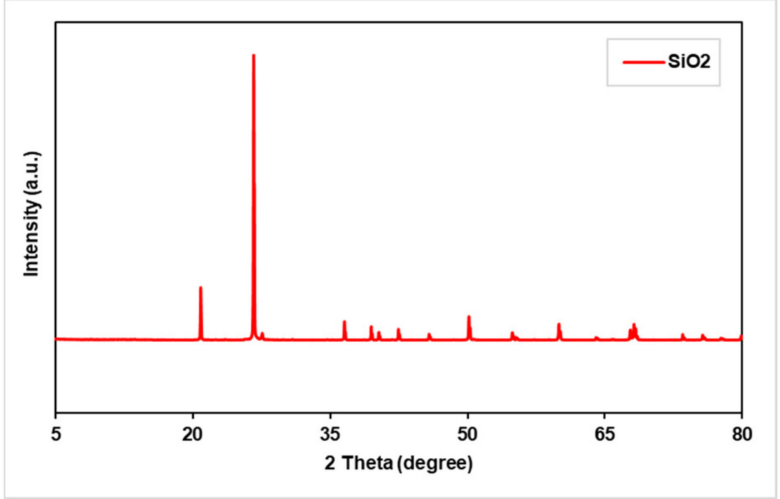

(c)

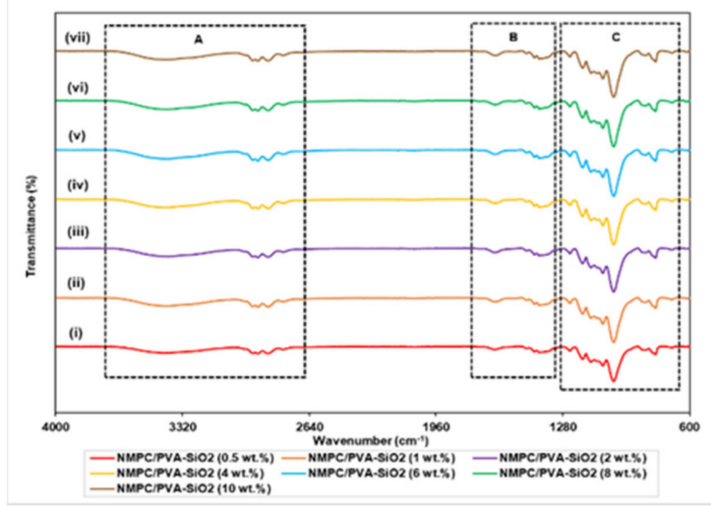

(b)

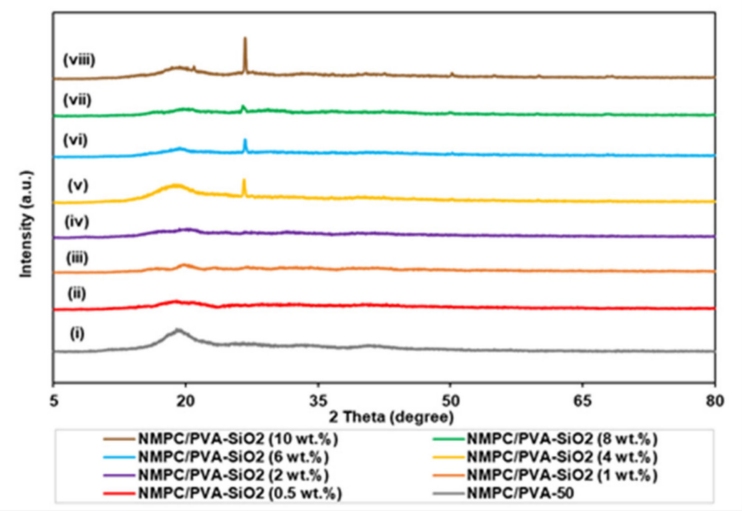

(d)

Figure 7. (a) FTIR spectra of $\mathrm{SiO}_{2}$ filler, NMPC/PVA-50 and NMPC/PVA-SiO 2 (4 wt.\%) composite membrane, (b) FTIR spectra of NMPC/PVA-SiO 2 composite membrane with different compositions, (c) XRD spectrum of commercial $\mathrm{SiO}_{2}$ filler obtained experimentally, and (d) XRD spectra of NMPC/PVA and NMPC/PVA-SiO 2 composite membrane with different compositions.

XRD analysis was performed to demonstrate the crystallinity and confirm changes in the degree of crystallinity of the $\mathrm{SiO}_{2}$ filler and $\mathrm{NMPC} / \mathrm{PVA}-\mathrm{SiO}_{2}$ composite membranes. Figure $7 \mathrm{c}$ illustrated the XRD spectrum of the commercial $\mathrm{SiO}_{2}$ filler obtained experimentally, which exhibited a highly crystalline structure with crystalline percentage of $91.5 \%$. Dominant crystalline peaks were observed at $2 \theta=20.89^{\circ}$ and $26.67^{\circ}$, representing $\mathrm{SiO}_{2}$ with a low type of cristobalite and a tetragonal shape (PDF Card No.: 01-076-0941) [64].

The NMPC/PVA-50 composite membrane showed the presence of an amorphous region at $2 \theta=19.50^{\circ}$ (Figure $7 \mathrm{~d}(\mathrm{i})$ ). Peaks at $2 \theta=19.50^{\circ}$ for all NMPC $/ \mathrm{PVA}-\mathrm{SiO}_{2}$ composite membranes with different compositions exhibited the presence of amorphous regions in each membrane and proved that both the NMPC/PVA polymer matrix and $\mathrm{SiO}_{2}$ filler were well dispersed (Figure 7d (ii-viii)). The presence of a diffraction peak at an angle of $2 \theta=26.67^{\circ}$ indicated the presence of $\mathrm{SiO}_{2}$ filler in the polymer matrix. The peak was not visible in the XRD spectrum with the addition of $0.5-2 \mathrm{wt} . \% \mathrm{SiO}_{2}$ filler into the polymer 
matrix. This invisible peak was likely due to the small amount of $\mathrm{SiO}_{2}$ loading; however, the peak was clearly visible when the $\mathrm{SiO}_{2}$ loading was increased up to $10 \mathrm{wt}$.\%. The uniformity factor of filler distributions in the membrane was likely to play a role in the existence of uneven peaks in the XRD spectrum. In addition, it can be observed that with the addition of $\mathrm{SiO}_{2}$ loadings of $0.5-4 \mathrm{wt}$.\%, the amorphous percentage of the composite membranes increased with the value of $71.8-77.7 \%$. The crystallinity of the membrane increased with the addition of $6-10 \mathrm{wt}$. $\% \mathrm{SiO}_{2}$, with the crystalline percentage of $24.9-28.2 \%$, consequently causing the proton conductivity of the NMPC/PVA-SiO 2 composite membranes with these compositions to decrease.

\subsubsection{Morphological Studies}

The morphology of the modified composite membrane with $\mathrm{SiO}_{2}$ filler (NMPC/PVA$\mathrm{SiO}_{2}$ ) was observed using FESEM and elemental mapping to observe the distribution of $\mathrm{SiO}_{2}$ filler in the polymer matrix. Figure 8 shows the FESEM micrographs of the cross-sectional views for the NMPC/PVA-SiO 2 composite membranes with different compositions. All composite membranes were observed to be homogeneously mixed, and the structure of the composite membranes appeared rough and fibrous with noticeable pores (Figure $8 \mathrm{a}-\mathrm{g}$ ). However, no phase separation occurred when the polymer matrix and $\mathrm{SiO}_{2}$ filler were mixed, hence proving that all of the materials were compatible with each other when producing the NMPC/PVA-SiO 2 composite membranes.

Figure 57 shows the FESEM micrographs of the elemental mapping for all NMPC/PVA$\mathrm{SiO}_{2}$ composite membranes with different $\mathrm{SiO}_{2}$ loadings in this study. The dispersion of inorganic filler in the polymer matrix had a large influence on the performance of the composite membranes. The structure of the $\mathrm{SiO}_{2}$ inorganic filler provided proton channels, and its dispersion affected the physical properties and conductivity of the composite membrane [20,65-67]. The uniform dispersion of $\mathrm{SiO}_{2}$ filler was very important for forming proton conduction channels, which consequently led to a high proton conductivity in the composite membrane. The $\mathrm{SiO}_{2}$ particles were dispersed uniformly, and no significant aggregation was observed in the FESEM images when $0.5-4 \mathrm{wt} . \% \mathrm{SiO}_{2}$ was added into the polymer matrix (Figure S7a-d). However, when the $\mathrm{SiO}_{2}$ loading was increased to values exceeding 6 wt.\% (Figure S7e-g), a uniform dispersion with a slight agglomeration of $\mathrm{SiO}_{2}$ particles was clearly visible in the polymer matrix. This tendency toward agglomeration at higher loadings was most likely due to the high and fine content of $\mathrm{SiO}_{2}$ particles, resulting in the occurrence of a high surface area with high surface energy, thus inducing increased agglomeration. The morphology observed through these FESEM images showed that when $\mathrm{SiO}_{2}$ particles were excessively added into the NMPC/PVA polymer matrix, they affected the performance of the composite membranes in regard to the proton conductivity, water uptake, and IEC.
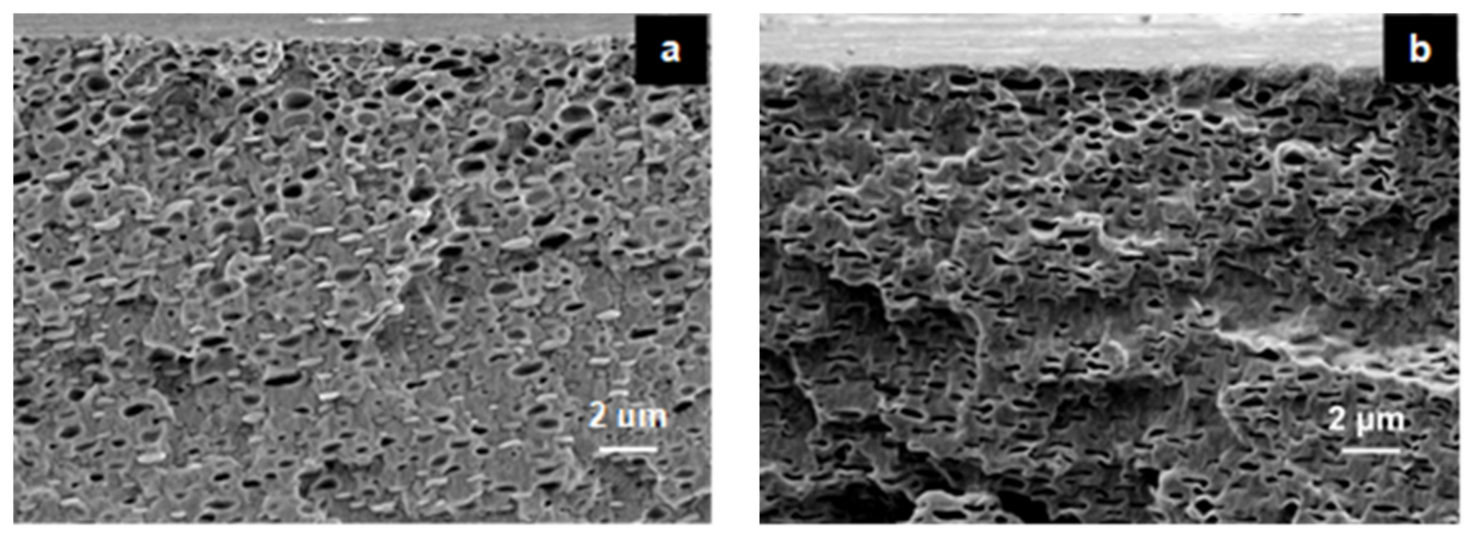

Figure 8. Cont. 


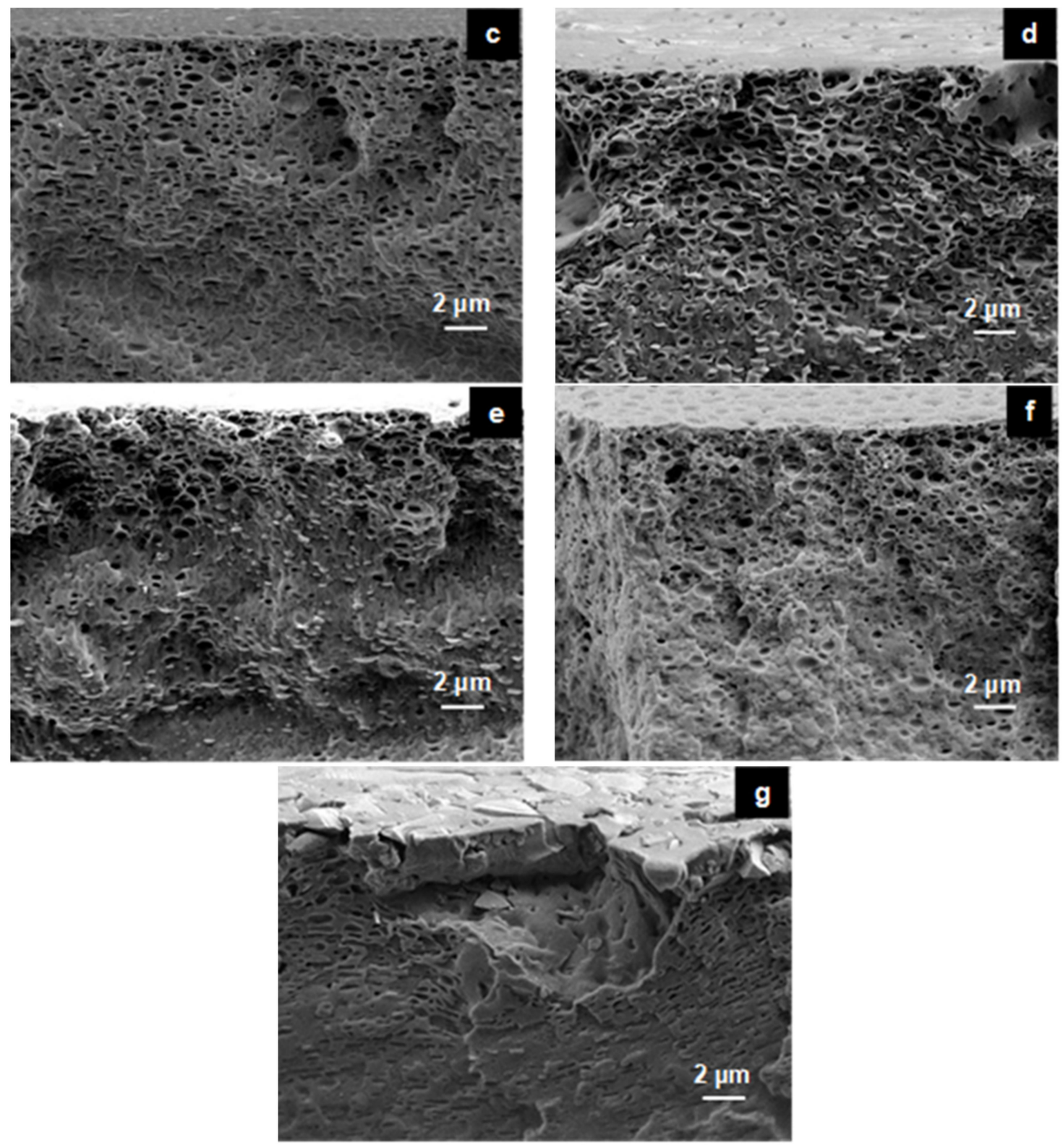

Figure 8. FESEM micrographs of the cross-sectional views of the (a) $\mathrm{NMPC}_{\mathrm{PVA}-\mathrm{SiO}_{2}(0.5 \mathrm{wt} . \%),(\mathbf{b}) \mathrm{NMPC} / \mathrm{PVA}-\mathrm{SiO}}^{2}$ (1 wt.\%), (c) NMPC/PVA-SiO 2 (2 wt.\%), (d) NMPC/PVA-SiO 2 (4 wt.\%), (e) NMPC/PVA-SiO 2 (6 wt.\%), (f) NMPC/PVA$\mathrm{SiO}_{2}(8$ wt.\%), and (g) NMPC/PVA-SiO 2 (10 wt.\%) composite membranes.

\subsubsection{Thermal Stability}

The thermal stability of the NMPC/PVA-50 composite membrane and NMPC/PVA$\mathrm{SiO}_{2}$ composite membranes was determined through TGA analysis to ensure their performance in fuel cell applications. The TGA curve of the NMPC/PVA composite membrane in Figure 9 shows three stages of weight loss, similar to those discussed in Section 3.2.3. The TGA curves shown in Figure 9 show that all produced NMPC/PVA-SiO 2 composite membranes (0.5-10 wt.\%) followed degradation behavior that was very similar to that of the unmodified NMPC/PVA composite membrane. Figure 9 (I, II, and III) exhibited that there were three stages of degradation in the thermogram for all produced $\mathrm{NMPC} / \mathrm{PVA}-\mathrm{SiO}_{2}$ composite membranes. The first stage of degradation occurred at the range of $100-150{ }^{\circ} \mathrm{C}$, with a weight loss of approximately $9-11 \%$ that was due to the loss of absorbed water content and weakly bound molecules in the membrane matrix. The second stage of degradation was due to the thermal degradation of the cross-linking network in 
the membrane, as well as the loss of PVA polymer and groups present in $\mathrm{SiO}_{2}$ in the range of $240-300{ }^{\circ} \mathrm{C}$. The third stage of degradation occurred at temperatures of approximately $380-470{ }^{\circ} \mathrm{C}$, which was caused by the thermal decomposition of the main polymer chain in the membrane matrix.

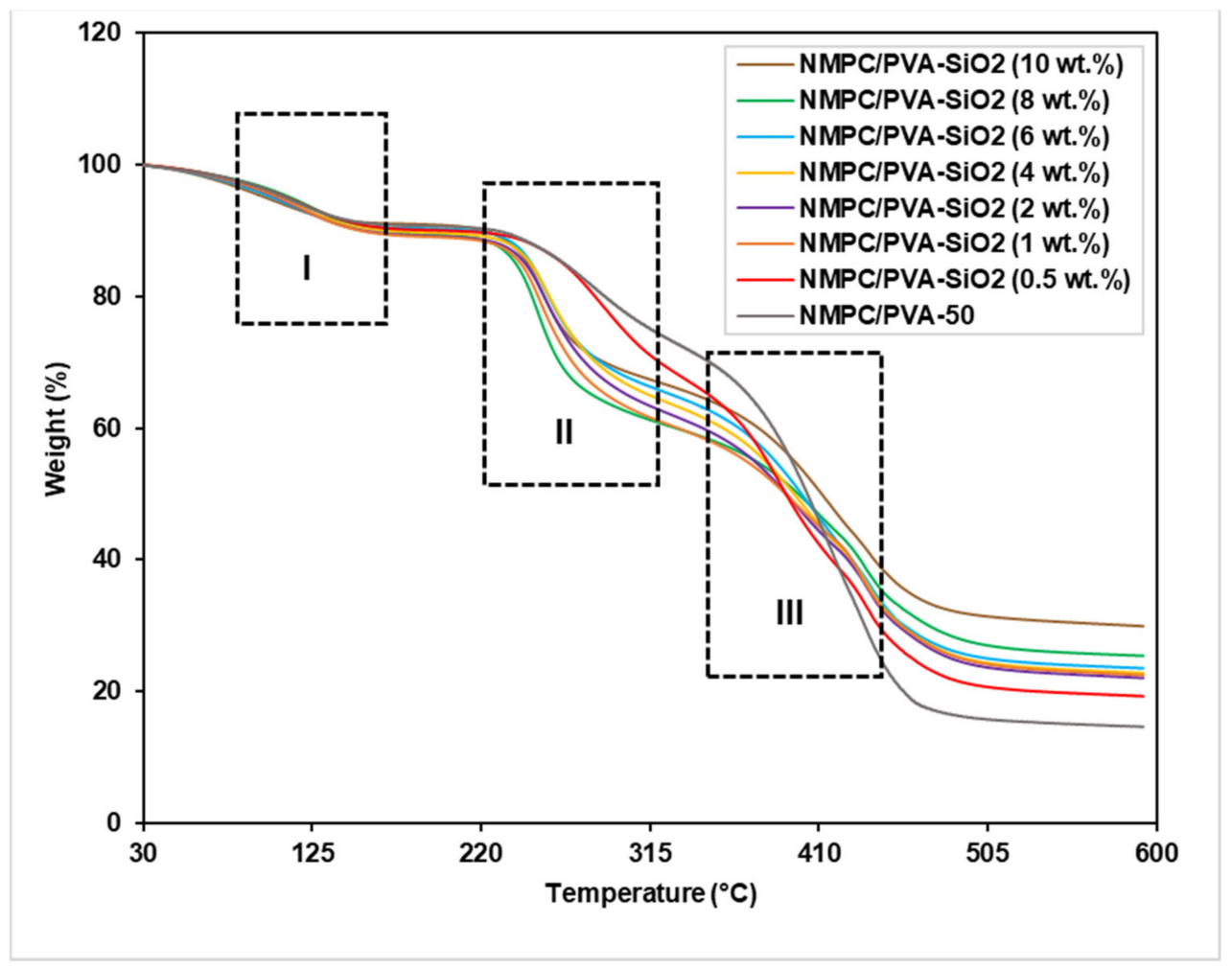

Figure 9. TGA curves of the NMPC/PVA-50 composite membrane and $\mathrm{NMPC} / \mathrm{PVA}^{-\mathrm{SiO}_{2}}$ composite membranes with different compositions.

It can be observed that from the TGA curves of NMPC/PVA-65 composite membrane (Figure 4) and NMPC/PVA-SiO 2 composite membranes (Figure 9), the main decomposition stage was very close or similar, which indicated that similar amount of component was decomposed as a function of temperature. However, the rate of decomposition might have changed after the heating and thermal degradation process. Based on the TGA curves and tables of thermal stability analysis (Tables S1 and S2), it can be seen that the onset or initial decomposition temperature has significantly increased from $80^{\circ} \mathrm{C}$ in NMPC/PVA-65 composite membrane to approximately $100^{\circ} \mathrm{C}$ in all of the NMPC/PVA$\mathrm{SiO}_{2}$ composite membranes, while the residues remained very close or similar in both types of membranes. The initial temperature of the main degradation peak in the first stage shifted to a higher temperature (from $80^{\circ} \mathrm{C}$ to $100^{\circ} \mathrm{C}$ ) when the $\mathrm{SiO}_{2}$ fillers were added to the membrane matrix, thereby showing increased thermal stability. Table $\mathrm{S} 2$ shows the thermal stability analysis of NMPC/PVA-50 composite membrane and NMPC/PVA$\mathrm{SiO}_{2}$ composite membranes (0.5-10 wt.\%) according to the three stages of degradation and weight loss (I, II, and III) as labeled in Figure 9. In addition, the NMPC/PVA-SiO 2 (10 wt.\%) composite membrane also exhibited a higher residue content or mass (approximately $30 \%$ ) than the NMPC/PVA-50 composite membrane without $\mathrm{SiO}_{2}$ filler $(17 \%)$ and other $\mathrm{NMPC} / \mathrm{PVA}-\mathrm{SiO}_{2}$ composite membranes with different compositions (20-28\%). This increase proved that chemical modification by the addition of $\mathrm{SiO}_{2}$ filler into the membrane matrix could improve the thermal stability of the resulting composite membrane for use in fuel cell applications, remaining stable in the desired operating temperature range of $80-100{ }^{\circ} \mathrm{C}$. 


\subsubsection{Dynamic Mechanical Analysis (DMA)}

A DMA analysis of the NMPC/PVA-SiO ${ }_{2}$ composite membranes was used to study the influence of different interactions between the membrane matrix and $\mathrm{SiO}_{2}$ filler on the mechanical properties of the composite membranes. Figure 10a-g shows the $\tan \delta$ and storage modulus against temperature for the $\mathrm{NMPC} / \mathrm{PVA}-\mathrm{SiO}_{2}$ composite membranes with different compositions, while Figure $\mathrm{S} 8$ shows the comparisons of $\tan \delta$ curves for all NMPC/PVA-SiO 2 composite membranes. Figure $10 \mathrm{a}-\mathrm{g}$ shows that $\mathrm{T}_{\mathrm{g}}$ occurred in the temperature range of $118-130{ }^{\circ} \mathrm{C}$ for all composite membranes. The $\tan \delta$ curve also displayed that the range of $\mathrm{T}_{\mathrm{g}}$ peak heights for all composite membranes was $0.5-0.7$, indicating that all membranes were in the amorphous phase. Figure 10 exhibited that the NMPC/PVA-SiO 2 (1 wt.\%) composite membrane has the highest $\mathrm{T}_{\mathrm{g}}$ peak value on the $\tan \delta$ curve which was around 0.7 with increasing amorphous phase. Other than that, the NMPC/PVA-SiO${ }_{2}$ composite membranes with $\mathrm{SiO}_{2}$ loadings of $6 \mathrm{wt} . \%$ and $10 \mathrm{wt}$. $\%$ showed lower $\mathrm{T}_{\mathrm{g}}$ peaks, with values around 0.5 , respectively, corresponding to the decrease of amorphous phase in the membrane, in which has been discussed on XRD analysis (Section 3.3.1). Based on all graphs (Figure 10a-g), another peak was likely to exist at temperatures below $35^{\circ} \mathrm{C}$, although the data displayed did not cover a sufficiently low temperature for full peak capture.

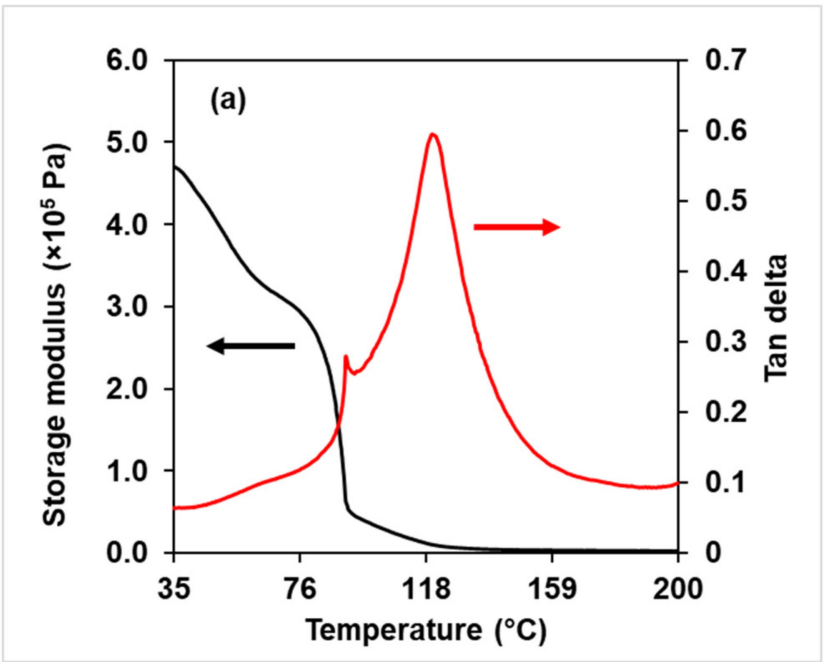

(a)

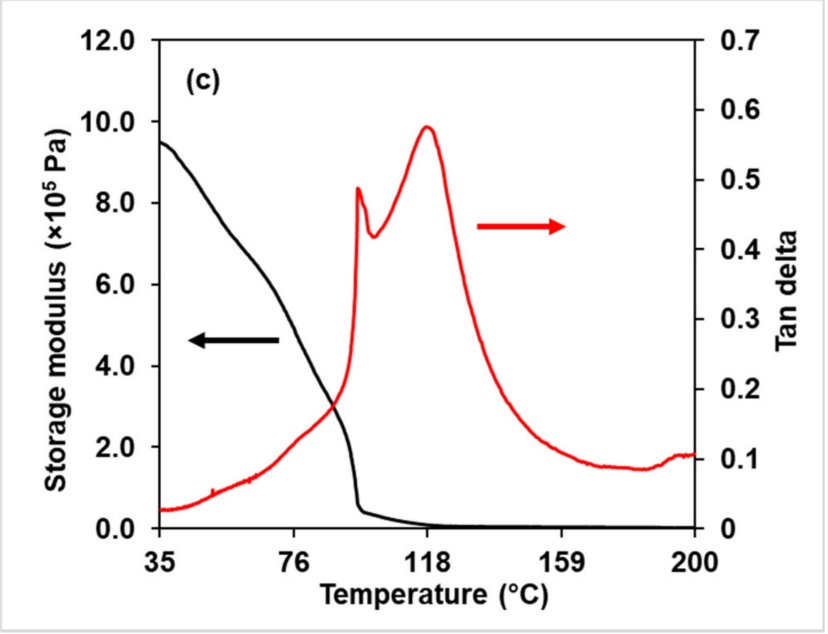

(c)

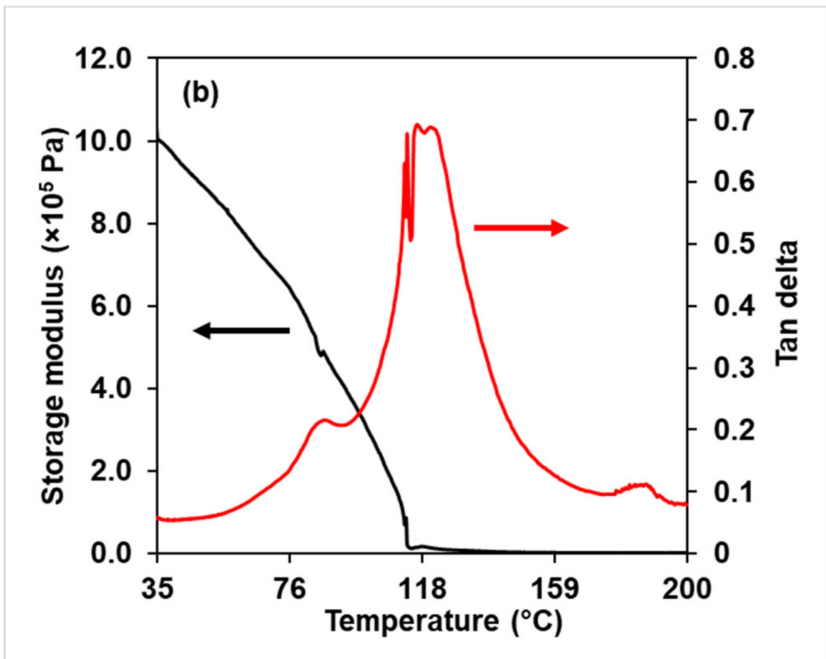

(b)

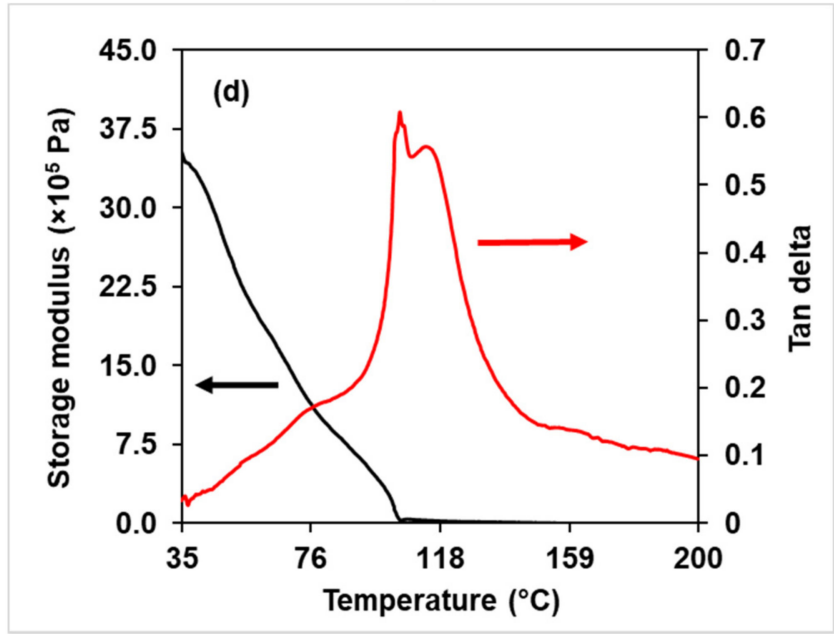

(d)

Figure 10. Cont. 


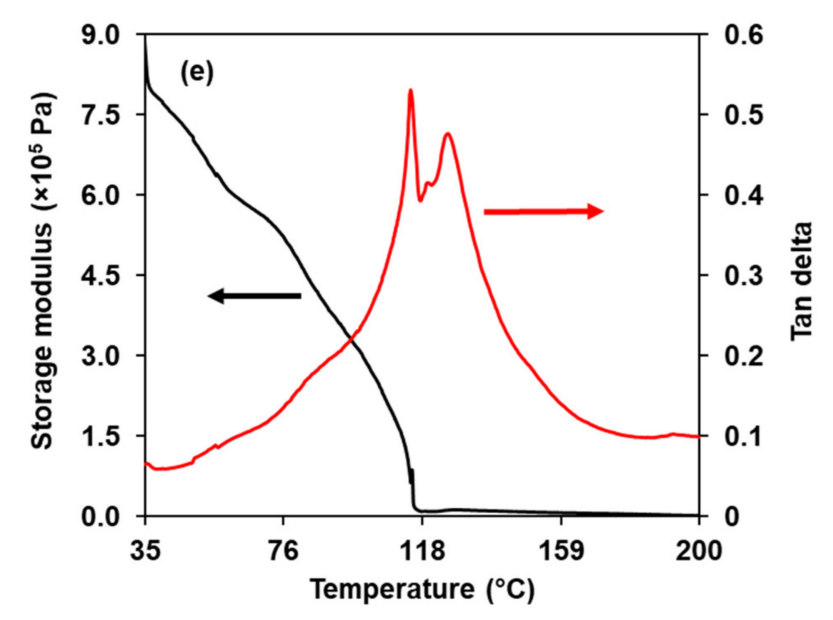

(e)

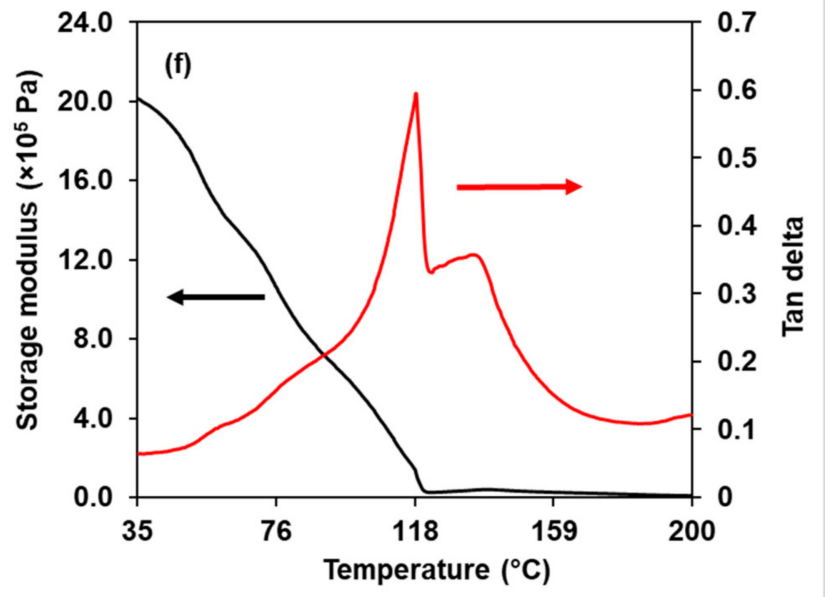

(f)

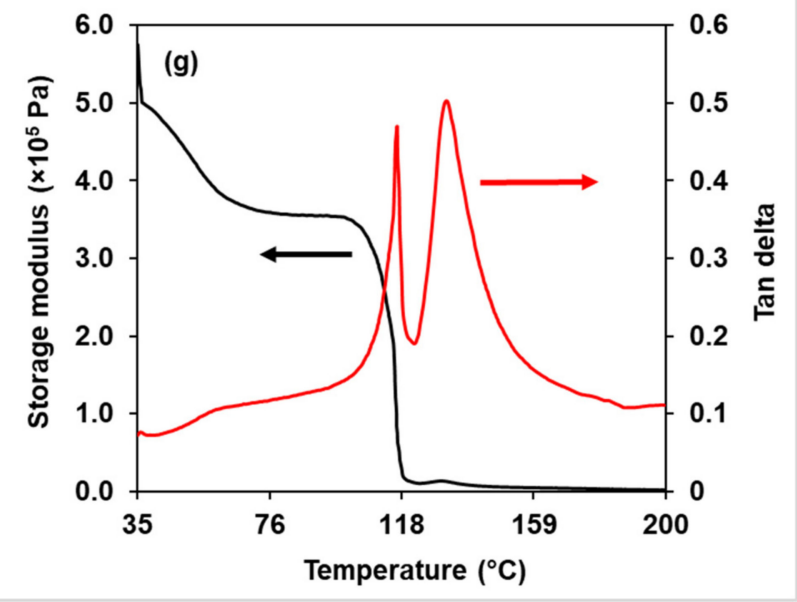

(g)

Figure 10. Tan $\delta$ and storage modulus of the (a) NMPC/PVA-SiO 2 (0.5 wt.\%), (b) $\mathrm{NMPC} / \mathrm{PVA}-\mathrm{SiO}_{2}(1 \mathrm{wt} . \%)$, (c) NMPC/PVA-SiO 2 (2 wt.\%), (d) NMPC/PVA-SiO 2 (4 wt.\%), (e) NMPC/PVA-SiO 2 (6 wt.\%), (f) NMPC/PVA-SiO 2 (8 wt.\%), and (g) NMPC/PVA-SiO 2 (10 wt.\%) composite membrane.

Besides that, Figure 10a-g also shows that two peaks appeared in all tan $\delta$ curves. The two or multiple tan $\delta$ peaks appeared in most polymers and the interpretation for this occurrence varies between the system of polymers. Different types or phases of polymers (crystalline, semi-crystalline, or amorphous) displayed different behavior or mechanisms due to temperature relaxations in the presented phase as well as the relative miscibility of the components in polymers. Moreover, the $\mathrm{T}_{\mathrm{g}}$ and modulus values will be affected due to the heating rate, test frequency, and polymer structures, such as polymer chain rigidity, polymer chain flexibility, crystallization, and the degree of cross-linking [55,57].

Figure 10a-g also shows the storage modulus of all NMPC/PVA-SiO ${ }_{2}$ composite membranes, and the value of the storage modulus for all composite membranes decreased with an increasing temperature until it reached a temperature of approximately $100^{\circ} \mathrm{C}$. Moreover, the trends shown for each storage modulus were considerably inconsistent, which might be due to the thickness of membranes and undetermined degree of crosslinking. When the $\mathrm{SiO}_{2}$ filler was added into the membrane matrix with a loading range of $0.5-4 \mathrm{wt} . \%$, the value of the storage modulus increased (around $4.80 \times 10^{5}-3.46 \times 10^{6} \mathrm{~Pa}$ ) and then experienced a slight decrease as the $\mathrm{SiO}_{2}$ content was further increased exceeding $4 \mathrm{wt} . \%$. This storage modulus value then increased slightly and continued to decrease $\left(5.00 \times 10^{5} \mathrm{~Pa}\right)$ when $\mathrm{SiO}_{2}$ loading of $10 \mathrm{wt} . \%$ was added into the membrane matrix. 
Despite having a slight decrease, the initial storage modulus value (at a temperature of approximately $30{ }^{\circ} \mathrm{C}$ ) could be maintained around $100{ }^{\circ} \mathrm{C}$ in the NMPC/PVA-SiO ${ }_{2}$ (10 wt.\%) composite membrane (Figure $10 \mathrm{~g}$ ), demonstrating the mechanical stability of the membrane and its potential use within the optimum range of low operating temperature $\left(80-100{ }^{\circ} \mathrm{C}\right)$ of fuel cell applications.

\subsubsection{Water Uptake, Swelling Ratio, Ion Exchange Capacity, and Proton Conductivity}

Effective proton transfer in the PEM depended on water molecules that provided proton transport and formed a network of hydrogen bonds in the membrane matrix. Therefore, a high water content was a major factor in obtaining a high proton conductivity. The water uptake, swelling area, and swelling thickness of the composite membrane were measured at room temperature and are listed in Table 2. The water uptake increased with an increasing $\mathrm{SiO}_{2}$ loading in the membrane matrix (45.7-55.7\%) and then experienced a slight decrease to a certain extent. The presence of fillers having hydrophilic groups ( $\mathrm{Si}-\mathrm{OH})$ in $\mathrm{SiO}_{2}$ that absorbed or attracted water was one of the factors that contributed to the increase in water uptake, as well as the uniform dispersion of fillers in the membrane matrix. The water uptake value obtained by the $\mathrm{NMPC} / \mathrm{PVA}-\mathrm{SiO}_{2}$ composite membrane was higher than that of the NMPC/PVA composite membranes without $\mathrm{SiO}_{2}$. The highest measured water uptake was $55.7 \%$ for the NMPC $/ \mathrm{PVA}-\mathrm{SiO}_{2}$ composite membrane (4 wt. $\%$ ). When the $\mathrm{SiO}_{2}$ loading was further increased to $8 \mathrm{wt} . \%$, the water uptake decreased (46.5\%), possibly due to the addition of excess filler, which reduced the size of the ion channels that served as the main water storage space in the membrane matrix [66]. The agglomeration of filler at high $\mathrm{SiO}_{2}$ loading concentrations also resulted in a reduction of number of polar groups (Si-OH) presented for the purpose of water uptake in the membrane [68].

Table 2 also exhibits the values of the swelling ratio, which were the swelling area and swelling thickness of all NMPC/PVA-SiO ${ }_{2}$ composite membranes. Generally, it is known that a higher water uptake can lead to a higher swelling ratio. Table 2 shows that both the swelling area and swelling thickness and water uptake show similar trends. The swelling ratio increased with an increasing water uptake value and decreased slightly as the water uptake percentage decreased. All NMPC/PVA-SiO ${ }_{2}$ composite membranes underwent a cross-linking process to avoid dissolution and to reduce excessive swelling of the composite membrane. The NMPC/PVA-SiO 2 composite membrane (4 wt.\%) showed the highest swelling ratio, which was correlated with the highest water uptake value than the NMPC/PVA-50 composite membrane. However, this membrane still demonstrated good stability when compared to the unmodified NMPC membrane. Nevertheless, there was no clear trend regarding the increase or decrease of the swelling ratios.

The IEC depended on the number of functional groups present in the composite membrane, which was also an indicator of the number of active groups present for each mass of material to facilitate ion transfer and proton conduction. Table 2 shows the IEC values of the NMPC/PVA-SiO 2 composite membranes with different compositions. The increase in $\mathrm{SiO}_{2}$ loadings (0.5-4 wt.\%) in the $\mathrm{NMPC} / \mathrm{PVA}-\mathrm{SiO}_{2}$ composite membranes increased the IEC magnitude from 0.43 to 0.56 mequiv $\mathrm{g}^{-1}$ and decreased as the $\mathrm{SiO}_{2}$ loadings were further increased. This increase in the IEC value was likely due to the active groups (Si-OH) in the filler that was mixed with the NMPC/PVA membrane matrix. The IEC trend is the same as the water uptake and swelling ratio, therefore when the water uptake and swelling ratio decreased, the IEC value also decreased. After the IEC value for NMPC/PVA-SiO ${ }_{2}$ composite membrane (6-8 wt.\%) decreased, there was a slight increase in the IEC value for NMPC/PVA-SiO ${ }_{2}$ composite membrane (10 wt.\%), which was due to the aggregation of filler material. However, the aggregation was likely to be more uniform compared to the presence of $\mathrm{SiO}_{2}$ filler with loadings of 6-8 wt.\%. This inconsistent trend might also be contributed by different degrees of cross-linking of composite membranes. 


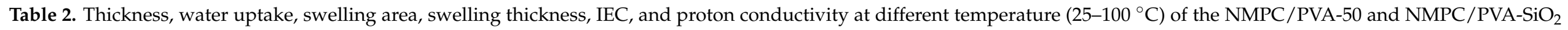
composite membranes with different compositions.

\begin{tabular}{|c|c|c|c|c|c|c|c|c|c|c|}
\hline \multirow{2}{*}{ Membrane Sample } & \multirow{2}{*}{$\begin{array}{l}\text { Thickness } \\
\text { (mm) }\end{array}$} & \multirow{2}{*}{$\begin{array}{c}\text { Water } \\
\text { Uptake (\%) }\end{array}$} & \multirow{2}{*}{$\begin{array}{l}\text { Swelling } \\
\text { Area (\%) }\end{array}$} & \multirow{2}{*}{$\begin{array}{c}\text { Swelling } \\
\text { Thickness (\%) }\end{array}$} & \multirow{2}{*}{$\begin{array}{c}\text { IEC } \\
\left(\text { mequiv }^{-1}\right)\end{array}$} & \multicolumn{5}{|c|}{ Proton Conductivity $\left(\mathbf{1 0}^{-4} \mathrm{~S} \mathrm{~cm}^{-1}\right)$} \\
\hline & & & & & & $25^{\circ} \mathrm{C}$ & $40^{\circ} \mathrm{C}$ & $60^{\circ} \mathrm{C}$ & $80^{\circ} \mathrm{C}$ & $100^{\circ} \mathrm{C}$ \\
\hline NMPC/PVA- 50 & $0.09 \pm 0.01$ & $51.9 \pm 2.3$ & $35.1 \pm 16.3$ & $62.2 \pm 3.3$ & $0.45 \pm 0.02$ & $0.87 \pm 0.02$ & $1.10 \pm 0.03$ & $1.69 \pm 0.01$ & $2.03 \pm 0.02$ & $2.22 \pm 0.01$ \\
\hline NMPC/PVA-SiO 2 (0.5 wt.\%) & $0.10 \pm 0.01$ & $45.7 \pm 2.0$ & $28.4 \pm 5.9$ & $44.6 \pm 8.8$ & $0.43 \pm 0.02$ & $1.14 \pm 0.04$ & $1.78 \pm 0.08$ & $2.22 \pm 0.01$ & $2.87 \pm 0.01$ & $3.20 \pm 0.06$ \\
\hline NMPC/PVA-SiO 2 (1 wt.\%) & $0.10 \pm 0.02$ & $47.1 \pm 1.8$ & $33.1 \pm 10.8$ & $48.3 \pm 4.9$ & $0.45 \pm 0.02$ & $1.36 \pm 0.07$ & $1.93 \pm 0.09$ & $2.47 \pm 0.10$ & $3.25 \pm 0.02$ & $3.81 \pm 0.05$ \\
\hline NMPC/PVA-SiO 2 (2 wt.\%) & $0.10 \pm 0.01$ & $47.4 \pm 2.8$ & $37.6 \pm 11.3$ & $52.9 \pm 3.6$ & $0.49 \pm 0.03$ & $1.63 \pm 0.06$ & $2.28 \pm 0.04$ & $3.42 \pm 0.14$ & $3.94 \pm 0.13$ & $4.41 \pm 0.14$ \\
\hline NMPC/PVA-SiO 2 (4 wt.\%) & $0.11 \pm 0.01$ & $55.7 \pm 1.9$ & $43.9 \pm 5.5$ & $63.1 \pm 1.0$ & $0.56 \pm 0.02$ & $1.90 \pm 0.09$ & $2.38 \pm 0.09$ & $3.51 \pm 0.07$ & $4.65 \pm 0.06$ & $5.08 \pm 0.05$ \\
\hline NMPC/PVA-SiO 2 (6 wt.\%) & $0.11 \pm 0.02$ & $50.6 \pm 1.9$ & $35.3 \pm 6.6$ & $55.8 \pm 4.8$ & $0.44 \pm 0.03$ & $1.82 \pm 0.07$ & $2.22 \pm 0.17$ & $3.42 \pm 0.11$ & $4.16 \pm 0.10$ & $4.67 \pm 0.09$ \\
\hline NMPC/PVA-SiO 2 (8 wt.\%) & $0.12 \pm 0.03$ & $46.5 \pm 1.2$ & $27.6 \pm 6.1$ & $51.4 \pm 5.1$ & $0.37 \pm 0.03$ & $1.56 \pm 0.08$ & $1.96 \pm 0.09$ & $2.79 \pm 0.10$ & $3.53 \pm 0.05$ & $4.38 \pm 0.08$ \\
\hline NMPC /PVA-SiO 2 (10 wt.\%) & $0.13 \pm 0.02$ & $48.8 \pm 1.2$ & $32.8 \pm 6.1$ & $54.1 \pm 8.2$ & $0.41 \pm 0.02$ & $1.71 \pm 0.16$ & $2.22 \pm 0.08$ & $3.05 \pm 0.09$ & $3.97 \pm 0.08$ & $4.53 \pm 0.05$ \\
\hline Nafion 212 & $0.02 \pm 0.01$ & - & - & - & - & $* 1.25 \pm 0.03$ & $* 1.58 \pm 0.05$ & $* 1.80 \pm 0.04$ & $* 2.06 \pm 0.03$ & $* 1.87 \pm 0.06$ \\
\hline
\end{tabular}


The fuel cell performance efficiency depended on the proton conductivity, which was also an important feature of a fuel cell membrane. The presence of water was very important for proton conduction in the membrane, thus proving that water uptake was closely related to the improvement in proton conductivity. The proton conductivity of commercial Nafion 212 membrane was measured experimentally under hydrated conditions. The proton conductivity of Nafion 212 has increased from $1.25 \times 10^{-2} \mathrm{~S} \mathrm{~cm}^{-1}$ (at $25^{\circ} \mathrm{C}$ ) to $2.06 \times 10^{-2} \mathrm{~S} \mathrm{~cm}^{-1}\left(\right.$ at $\left.80{ }^{\circ} \mathrm{C}\right)$, and then decreased when the temperature reached $100{ }^{\circ} \mathrm{C}$ due to membrane deterioration. As expected, the proton conductivities of Nafion 212 are higher by two orders of magnitude compared to the NMPC/PVA and NMPC/PVA-SiO 2 membranes in the study. The proton conductivity of the NMPC/PVA-SiO 2 composite membranes with different compositions was measured from $25-100{ }^{\circ} \mathrm{C}$ under hydrated

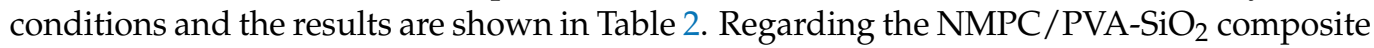
membranes, it was observed that the proton conductivity increased with an increasing $\mathrm{SiO}_{2}$ loadings in the membrane matrix with a loading range of $0.5-4 \mathrm{wt}$.\% (3.20-5.08 $\times$ $10^{-4} \mathrm{~S} \mathrm{~cm}^{-1}$ at $100{ }^{\circ} \mathrm{C}$ ). The proton conductivity increased with an increasing temperature due to the increase in flexibility of the polymer chain and the mobility of water molecules at high temperature. Moreover, the presence of the -OH groups on $\mathrm{SiO}_{2}$ might also provide additional conduction sites for proton transfer. The proton conductivity decreased when $\mathrm{SiO}_{2}$ was added up to $8 \mathrm{wt} . \%\left(4.38 \times 10^{-4} \mathrm{~S} \mathrm{~cm}^{-1}\right.$ at $\left.100{ }^{\circ} \mathrm{C}\right)$ and then increased slightly when 10 wt. $\% \mathrm{SiO}_{2}$ was added into the membrane matrix.

The changes in proton conductivity were due to several reasons, namely, when the $\mathrm{SiO}_{2}$ loading was less than $4 \mathrm{wt}$.\%, the fine and uniform dispersion of $\mathrm{SiO}_{2}$ in the membrane matrix promoted a decrease in crystallinity and caused the amorphous phase con-tent to increase. This amorphous phase changes have promoted proton transport through the membrane. Moreover, the interaction of hydrogen bonds between the membrane matrix and $\mathrm{SiO}_{2}$ could also induce the formation of continuous proton transport channels in the membrane. In addition, the increase in water uptake was beneficial for proton mobility and hydrogen bonding network formation. However, when the $\mathrm{SiO}_{2}$ loading reached 6-10 wt.\%, as seen in the FESEM mapping image (Figure S7), the agglomeration of $\mathrm{SiO}_{2}$ in the membrane matrix could result in proton conduction pathways with high tortuosity, thus decreasing the proton conductivity to a certain extent [69]. Therefore, based on the results shown in Table 2, the NMPC/PVA-SiO 2 (4 wt.\%) composite membrane exhibited the highest proton conductivity, which was $5.08 \times 10^{-4} \mathrm{~S} \mathrm{~cm}^{-1}$ at $100{ }^{\circ} \mathrm{C}$. This increase in proton conductivity was better than that of the NMPC/PVA-50 composite membranes without $\mathrm{SiO}_{2}\left(2.22 \times 10^{-4} \mathrm{~S} \mathrm{~cm}^{-1}\right.$ at $\left.100^{\circ} \mathrm{C}\right)$, thereby supporting that the improvement in conductivity performance was due to the presence of the hygroscopic filler $\mathrm{SiO}_{2}$. However, in this study, the NMPC/PVA-SiO 2 (4 wt.\%) composite membrane was not used to proceed for fuel cell polarization testing because of its low conductivity magnitude $\left(10^{-4} \mathrm{~S} \mathrm{~cm}^{-1}\right)$. The fabrication of MEA with this NMPC/PVA-SiO 2 membrane will further increase the ohmic losses, consequently, leading to mass transport losses and performance losses of a fuel cell.

All membrane samples exhibited a positive temperature-dependent proton conductivity, indicating an activated thermal process. The regression values obtained from the linear line were approximately $\mathrm{R}^{2} \approx 1$, and the proton conductivity increased with an increasing temperature for all composite membranes, which can be expressed via Arrhenius plots using the following equation [70]:

$$
\ln \sigma=-\frac{1000 \mathrm{E}_{\mathrm{a}}}{\mathrm{RT}}
$$

where $\sigma$ is the proton conductivity, $R$ is the universal gas constant $\left(8.314 \mathrm{~J} \mathrm{~mol}^{-1} \mathrm{~K}^{-1}\right), \mathrm{E}_{\mathrm{a}}$ is the activation energy $(\mathrm{kJ} / \mathrm{mol})$, and T refers to the absolute temperature $(\mathrm{K})$.

The activation energy or minimum energy required for proton conduction over the membrane could be obtained from the slope of the linear line (Figure S9). The NMPC/PVA- 
$\mathrm{SiO}_{2}$ (4 wt.\%) composite membrane showed an activation energy of $11.87 \mathrm{~kJ} / \mathrm{mol}$, which was lower than the activation energy of the NMPC/PVA-50 composite membrane without $\mathrm{SiO}_{2}(12.09 \mathrm{~kJ} / \mathrm{mol})$. The achieved activation energy could be attributed to the Grotthuss mechanism, which includes values of less than $15 \mathrm{~kJ} / \mathrm{mol}$ [71]. The above activation energy value was also supported when the addition of $\mathrm{SiO}_{2}$ induced the generation of a continuous proton conduction network for rapid proton transportation with low energy resistance through the Grotthuss mechanism. Furthermore, the linear lines obtained from the Arrhenius plots for the conductivity values indicated that the proton conduction mechanism was primarily determined by Grotthuss or hopping conductor species. The deviation of several points from the linear plots in the composite membranes suggested that the vehicle mechanism might also contribute to proton conduction [72].

In addition, Table 3 exhibited the comparisons of Nafion-based membranes, PVAbased membranes, and chitosan-based membranes in term of their water uptake, IEC and proton conductivity properties. Based on the Table 3, it can be observed that PVA-based and chitosan-based membranes possessed lower proton conductivity than Nafion-based membranes. However, the proton conductivities for both PVA-based and chitosan-based membranes were comparable. Even though the unmodified NMPC membrane that has been studied in this work showed the lowest proton conductivity, however, the conductivity could be enhanced with further modifications on the NMPC membrane and led to the improvement of one or two magnitudes. Other than that, the $\mathrm{NMPC} / \mathrm{PVA}-\mathrm{SiO}_{2} \mathrm{Composite}$ membrane seemed to have better proton conductivity than most of the chitosan-based and PVA-based membranes listed in the table or comparable to them though cannot be compared to the Nafion-based membranes.

Table 3. Comparisons of water uptake, IEC, and proton conductivity for Nafion-based membranes, PVA-based membranes, and chitosan-based membranes.

\begin{tabular}{|c|c|c|c|c|c|}
\hline Membrane & $\begin{array}{c}\text { Water } \\
\text { Uptake (\%) }\end{array}$ & $\begin{array}{c}\text { IEC } \\
\left(\text { mequiv }^{-1}\right)\end{array}$ & $\begin{array}{l}\text { Proton Conductivity } \\
\qquad\left(\mathrm{S} \mathrm{cm}^{-1}\right)\end{array}$ & Applications & References \\
\hline PVdF-coHFP/Nafion & 33.8 & - & $1.00 \times 10^{-3}$ & DMFC & {$[73]$} \\
\hline Nafion-sulfonated PVdF coated & 13.0 & - & $5.91 \times 10^{-3}$ & DMFC & [74] \\
\hline CS/PVS-Nafion & 29.1 & - & $7.01 \times 10^{-2}$ & DMFC & [75] \\
\hline Nafion/CNT & 29.5 & 0.90 & $7.35 \times 10^{-2}$ & DMFC & [76] \\
\hline Nafion 212 & - & - & $2.06 \times 10^{-2}$ & PEM & This study \\
\hline SPVA-SPTA & 150.4 & 0.45 & $8.80 \times 10^{-4}$ & PEM & [77] \\
\hline PVA-CS-CNC & 78 & - & $6.42 \times 10^{-4}$ & DMFC & [78] \\
\hline CS/SPVA-SSA & 220 & 2.60 & $2.58 \times 10^{-4}$ & PEM & {$[77]$} \\
\hline $\mathrm{Ph} / \mathrm{CS}-\mathrm{NH}_{4} \mathrm{SCN}$ & - & - & $2.42 \times 10^{-5}$ & PEM & [79] \\
\hline NMPC & - & - & $2.74 \times 10^{-6}$ & PEM & This study \\
\hline NMPC-OMPk & - & - & $1.43 \times 10^{-5}$ & PEM & [41] \\
\hline NMPC/PVA & 51.9 & 0.45 & $2.22 \times 10^{-4}$ & PEM & This study \\
\hline NMPC/PVA-SiO 2 & 55.7 & 0.56 & $5.08 \times 10^{-4}$ & PEM & This study \\
\hline
\end{tabular}

\section{Conclusions}

In summary, this work proved that chitosan could be successfully modified through the phosphorylation process, which introduced phosphonic acid groups to convert chitosan into $N$-methylene phosphonic chitosan (NMPC). This modification produced a watersoluble functionalized polymer that had a high degree of hydrophilicity compared to pristine chitosan, which is insoluble in water. The effect of different NMPC biopolymer contents in the NMPC/PVA composite membranes was thoroughly studied in this work. The NMPC/PVA composite membranes were prepared by varying the composition of NMPC (30-70\%) in the membrane, and physical and chemical characterizations were carried out. Based on the results obtained from the analyses, it could be concluded that the NMPC/PVA composite membrane with an NMPC content of $50 \mathrm{wt}$ \% showed the best performance among the other produced membranes in regard to the proton conductivity, 
water uptake, and IEC $\left(8.76 \times 10^{-5} \mathrm{~S} \mathrm{~cm}^{-1}, 51.9 \%\right.$, and 0.45 mequiv $\mathrm{g}^{-1}$, respectively). In addition, this membrane could be further improved by the addition of hygroscopic filler into the membrane matrix. As the NMPC/PVA-50 composite membrane showed the best performance, this membrane was chosen as the base membrane to be modified with the addition of different loadings (0.5-10 wt.\%) of inorganic filler $\left(\mathrm{SiO}_{2}\right)$. The results were expected to improve, and it was proven that the NMPC/PVA-SiO 2 (4 wt.\%) composite membrane exhibited the highest proton conductivity of $5.08 \times 10^{-4} \mathrm{~S} \mathrm{~cm}^{-1}$ at $100{ }^{\circ} \mathrm{C}$ with an IEC value of 0.56 mequiv $\mathrm{g}^{-1}$. The $\mathrm{NMPC} / \mathrm{PVA}-\mathrm{SiO}_{2}$ composite membrane displayed better performance than the unmodified NMPC/PVA membrane. However, the NMPC/PVA-based membranes were not comparable to the commercial Nafion membrane. Nevertheless, this chitosan-based membranes could be potentially used as PEM due to few advantages and properties including low-cost, biodegradable and could be used in other low power applications. Hence, further research will be conducted in the future, by replacing the inorganic filler with ionic liquids, which is expected to increase the conductivity values. In conclusion, the NMPC/PVA-based composite membrane needs extensive enhancement, especially on the conductivity value before the membrane could potentially be used as a PEM in fuel cell applications.

Supplementary Materials: The following are available online at https: / www.mdpi.com/article/ 10.3390/membranes11090675/s1. Figure S1: The enlarged images of the FTIR spectra of chitosan. Figure S2: The enlarged images of the FTIR spectra of NMPC/PVA composite membranes. Figure S3: Digital images of NMPC membrane and NMPC/PVA composite membrane. Figure S4: Comparisons of tan delta curves for NMPC/PVA membranes with different compositions. Figure S5: Nyquist plots for the NMPC membrane and NMPC/PVA composite membranes with different compositions. Figure S6: The enlarged images of the FTIR spectra of $\mathrm{NMPC} / \mathrm{PVA}-\mathrm{SiO}_{2}$ composite membranes. Figure S7: FESEM micrographs of the elemental mapping of the NMPC $/ \mathrm{PVA}-\mathrm{SiO}_{2}$ (0.5 wt.\%), NMPC/PVA-SiO 2 (1 wt.\%), NMPC/PVA-SiO 2 (2 wt.\%), NMPC/PVA-SiO 2 (4 wt.\%), $\mathrm{NMPC} / \mathrm{PVA}_{-} \mathrm{SiO}_{2}$ (6 wt.\%), NMPC/PVA-SiO 2 (8 wt.\%), and NMPC/PVA-SiO 2 (10 wt.\%) composite membranes. Figure S8: Comparisons of tan delta curves for NMPC/PVA-SiO $\mathrm{N}_{2}$ membranes with different compositions. Figure S9: Arrhenius plots of the NMPC/PVA and NMPC/PVA-SiO $\mathrm{Composite}_{2}$ membranes. Table S1: Thermal stability analysis of NMPC membrane and NMPC/PVA composite membranes with different compositions. Table S2: Thermal stability analysis of NMPC/PVA-50 composite membrane and NMPC/PVA-SiO2 composite membranes with different compositions.

Author Contributions: Conceptualization, N.A.H.R. and K.S.L.; methodology, N.A.H.R.; software, N.A.H.R..; validation, N.A.H.R. and K.S.L..; formal analysis, N.A.H.R.; investigation, N.A.H.R.; resources, K.S.L.; data curation, N.A.H.R.; writing—original draft preparation, N.A.H.R.; writingreview and editing, N.A.H.R. and K.S.L.; visualization, N.A.H.R.; supervision, K.S.L., W.Y.W., T.K.L. and A.A.; project administration, K.S.L.; funding acquisition, K.S.L. and T.K.L. All authors have read and agreed to the published version of the manuscript.

Funding: This research received funding from the Malaysian Ministry of Higher Education through Fundamental Research Grant Scheme (FRGS/1/2018/STG01/UKM/02/15) and Universiti Kebangsaan Malaysia (UKM) through the University Research Grants (GUP-2018-136 \& Dana Pecutan Penerbitan SELFUEL).

Institutional Review Board Statement: Not applicable.

Data Availability Statement: Not applicable.

Acknowledgments: The authors would like to acknowledge the support of human capital development given by Universiti Kebangsaan Malaysia.

Conflicts of Interest: The authors declare no conflict of interest.

\section{References}

1. Peighambardoust, S.J.; Rowshanzamir, S.; Amjadi, M. Review of the Proton Exchange Membranes for Fuel Cell Applications; Elsevier Ltd: Amsterdam, The Netherlands, 2010; Volume 35, ISBN 2177491223.

2. Chen, Q.; Zhang, G.; Zhang, X.; Sun, C.; Jiao, K.; Wang, Y. Thermal management of polymer electrolyte membrane fuel cells: A review of cooling methods, material properties, and durability. Appl. Energy 2021, 286, 116496. [CrossRef] 
3. Adiera, N.; Rosli, H.; Loh, K.S.; Wong, W.Y.; Yunus, R.M.; Lee, T.K.; Ahmad, A.; Chong, S.T. Review of Chitosan-Based Polymers as Proton Exchange Membranes and Roles of Chitosan-Supported Ionic Liquids. Int. J. Mol. Sci. 2020, $21,632$.

4. Alaswad, A.; Omran, A.; Sodre, J.R.; Wilberforce, T.; Pignatelli, G.; Dassisti, M.; Baroutaji, A.; Olabi, A.G. Technical and commercial challenges of proton-exchange membrane (Pem) fuel cells. Energies 2021, 14, 144. [CrossRef]

5. Wan, Y.; Creber, K.A.M.; Peppley, B.; Bui, V.T. Ionic conductivity of chitosan membranes. Polymer 2003, 44, 1057-1065. [CrossRef]

6. López-Chávez, E.; Martínez-Magadán, J.M.; Oviedo-Roa, R.; Guzmán, J.; Ramírez-Salgado, J.; Marín-Cruz, J. Molecular modeling and simulation of ion-conductivity in chitosan membranes. Polymer 2005, 46, 7519-7527. [CrossRef]

7. Wan, Y.; Creber, K.A.M.; Peppley, B.; Bui, V.T. Synthesis, characterization and ionic conductive properties of phosphorylated chitosan membranes. Macromol. Chem. Phys. 2003, 204, 850-858. [CrossRef]

8. Jayakumar, R.; Selvamurugan, N.; Nair, S.V.; Tokura, S.; Tamura, H. Preparative methods of phosphorylated chitin and chitosanAn overview. Int. J. Biol. Macromol. 2008, 43, 221-225. [CrossRef]

9. Ramos, V.M.; Rodríguez, N.M.; Díaz, M.F.; Rodríguez, M.S.; Heras, A.; Agulló, E. N-methylene phosphonic chitosan. Effect of preparation methods on its properties. Carbohydr. Polym. 2003, 52, 39-46. [CrossRef]

10. Binsu, V.V.; Nagarale, R.K.; Shahi, V.K.; Ghosh, P.K. Studies on N-methylene phosphonic chitosan/poly(vinyl alcohol) composite proton-exchange membrane. React. Funct. Polym. 2006, 66, 1619-1629. [CrossRef]

11. Saxena, A.; Kumar, A.; Shahi, V.K. Preparation and characterization of N-methylene phosphonic and quaternized chitosan composite membranes for electrolyte separations. J. Colloid Interface Sci. 2006, 303, 484-493. [CrossRef] [PubMed]

12. Datta, P.; Dhara, S.; Chatterjee, J. Hydrogels and electrospun nanofibrous scaffolds of N-methylene phosphonic chitosan as bioinspired osteoconductive materials for bone grafting. Carbohydr. Polym. 2012, 87, 1354-1362. [CrossRef]

13. Dadhich, P.; Das, B.; Dhara, S. Microwave assisted rapid synthesis of N-methylene phosphonic chitosan via Mannich-type reaction. Carbohydr. Polym. 2015, 133, 345-352. [CrossRef] [PubMed]

14. Ramos, V.M.; Rodríguez, M.S.; Agulló, E.; Rodríguez, N.M.; Heras, A. Chitosan with phosphonic and carboxylic group: New multidentate ligands. Int. J. Polym. Mater. Polym. Biomater. 2002, 51, 711-720. [CrossRef]

15. Albu, A.M.; Maior, I.; Nicolae, C.A.; Bocăneală, F.L. Novel Pva Proton Conducting Membranes Doped With Polyaniline Generated By in-Situ Polymerization. Electrochim. Acta 2016, 211, 911-917. [CrossRef]

16. Di Noto, V.; Boaretto, N.; Negro, E.; Pace, G. New inorganic-organic proton conducting membranes based on Nafion and hydrophobic fluoroalkylated silica nanoparticles. J. Power Sources 2010, 195, 7734-7742. [CrossRef]

17. Dupuis, A.C. Proton exchange membranes for fuel cells operated at medium temperatures: Materials and experimental techniques. Prog. Mater. Sci. 2011, 56, 289-327. [CrossRef]

18. Sun, C.; Negro, E.; Vezzù, K.; Pagot, G.; Cavinato, G.; Nale, A.; Herve Bang, Y.; Di Noto, V. Hybrid inorganic-organic protonconducting membranes based on SPEEK doped with WO3 nanoparticles for application in vanadium redox flow batteries. Electrochim. Acta 2019, 309, 311-325. [CrossRef]

19. Sun, C.; Negro, E.; Nale, A.; Pagot, G.; Vezzù, K.; Zawodzinski, T.A.; Meda, L.; Gambaro, C.; Di Noto, V. An efficient barrier toward vanadium crossover in redox flow batteries: The bilayer [Nafion/(WO3) x] hybrid inorganic-organic membrane. Electrochim. Acta 2021, 378, 138133. [CrossRef]

20. Vijayakumar, V.; Khastgir, D. Hybrid composite membranes of chitosan/sulfonated polyaniline/silica as polymer electrolyte membrane for fuel cells. Carbohydr. Polym. 2018, 179, 152-163. [CrossRef]

21. Dreyer, D.R.; Park, S.; Bielawski, C.W.; Ruoff, R.S. The chemistry of graphene oxide. Chem. Soc. Rev. 2010, 39, 228-240. [CrossRef]

22. Hatakeyama, K.; Karim, M.R.; Ogata, C.; Tateishi, H.; Funatsu, A.; Taniguchi, T.; Koinuma, M.; Hayami, S.; Matsumoto, Y. Proton conductivities of graphene oxide nanosheets: Single, multilayer, and modified nanosheets. Angew. Chemie-Int. Ed. 2014, 53, 6997-7000. [CrossRef] [PubMed]

23. Choi, B.G.; Hong, J.; Park, Y.C.; Jung, D.H.; Hong, W.H.; Hammond, P.T.; Park, H. Innovative polymer nanocomposite electrolytes: Nanoscale manipulation of ion channels by functionalized graphenes. ACS Nano 2011, 5, 5167-5174. [CrossRef]

24. Ou, X.; Jiang, L.; Chen, P.; Zhu, M.; Hu, W.; Liu, M.; Zhu, J.; Ju, H. Highly stable graphene-based multilayer films immobilized via covalent bonds and their applications in organic field-effect transistors. Adv. Funct. Mater. 2013, 23, 2422-2435. [CrossRef]

25. Tseng, C.Y.; Ye, Y.S.; Cheng, M.Y.; Kao, K.Y.; Shen, W.C.; Rick, J.; Chen, J.C.; Hwang, B.J. Sulfonated polyimide proton exchange membranes with graphene oxide show improved proton conductivity, methanol crossover impedance, and mechanical properties. Adv. Energy Mater. 2011, 1, 1220-1224. [CrossRef]

26. Zarrin, H.; Higgins, D.; Jun, Y.; Chen, Z.; Fowler, M. Functionalized graphene oxide nanocomposite membrane for low humidity and high temperature proton exchange membrane fuel cells. J. Phys. Chem. C 2011, 115, 20774-20781. [CrossRef]

27. Bai, H.; Li, Y.; Zhang, H.; Chen, H.; Wu, W.; Wang, J.; Liu, J. Anhydrous proton exchange membranes comprising of chitosan and phosphorylated graphene oxide for elevated temperature fuel cells. J. Memb. Sci. 2015, 495, 48-60. [CrossRef]

28. Mohd Nasir, N.F.; Zain, N.M.; Raha, M.G.; Kadri, N.A. Characterization of Chitosan-poly (Ethylene Oxide) Blends as Haemodialysis Membrane. Am. J. Appl. Sci. 2005, 2, 1578-1583. [CrossRef]

29. Mansur, H.S.; de S. Costa, E., Jr.; Mansur, A.A.P.; Barbosa-Stancioli, E.F. Cytocompatibility evaluation in cell-culture systems of chemically crosslinked chitosan/PVA hydrogels. Mater. Sci. Eng. C 2009, 29, 1574-1583. [CrossRef]

30. Wang, J.; Wang, X.; Xu, C.; Zhang, M.; Shang, X. Preparation of graphene/poly(vinyl alcohol) nanocomposites with enhanced mechanical properties and water resistance. Polym. Int. 2011, 60, 816-822. [CrossRef] 
31. Santos, C.; Silva, C.J.; Büttel, Z.; Guimarães, R.; Pereira, S.B.; Tamagnini, P.; Zille, A. Preparation and characterization of polysaccharides/PVA blend nanofibrous membranes by electrospinning method. Carbohydr. Polym. 2014, 99, 584-592. [CrossRef]

32. Smitha, B.; Sridhar, S.; Khan, A.A. Synthesis and characterization of poly(vinyl alcohol)-based membranes for direct methanol fuel cell. J. Appl. Polym. Sci. 2005, 95, 1154-1163. [CrossRef]

33. Xiong, Y.; Liu, Q.L.; Zhang, Q.G.; Zhu, A.M. Synthesis and characterization of cross-linked quaternized poly(vinyl alcohol)/chitosan composite anion exchange membranes for fuel cells. J. Power Sources 2008, 183, 447-453. [CrossRef]

34. Ming Yang, J.; Chih Chiu, H. Preparation and characterization of polyvinyl alcohol/chitosan blended membrane for alkaline direct methanol fuel cells. J. Memb. Sci. 2012, 419-420, 65-71. [CrossRef]

35. El Miri, N.; Abdelouahdi, K.; Zahouily, M.; Fihri, A.; Barakat, A.; Solhy, A.; El Achaby, M. Bio-nanocomposite films based on cellulose nanocrystals filled polyvinyl alcohol/chitosan polymer blend. J. Appl. Polym. Sci. 2015, 132, 42004. [CrossRef]

36. Yusoff, Y.N.; Loh, K.S.; Wong, W.Y.; Daud, W.R.W.; Lee, T.K. Sulfonated graphene oxide as an inorganic filler in promoting the properties of a polybenzimidazole membrane as a high temperature proton exchange membrane. Int. J. Hydrogen Energy 2020, 45, 27510-27526. [CrossRef]

37. Staiti, P.; Lufrano, F.; Aricò, A.S.; Passalacqua, E.; Antonucci, V. Sulfonated polybenzimidazole membranes-Preparation and physico-chemical characterization. J. Memb. Sci. 2001, 188, 71-78. [CrossRef]

38. Fadzallah, I.A.; Majid, S.R.; Careem, M.A.; Arof, A.K. A study on ionic interactions in chitosan-oxalic acid polymer electrolyte membranes. J. Memb. Sci. 2014, 463, 65-72. [CrossRef]

39. Amaral, I.F.; Granja, P.L.; Barbosa, M.A. Chemical modification of chitosan by phosphorylation: An XPS, FT-IR and SEM study. J. Biomater. Sci. Polym. Ed. 2005, 16, 1575-1593. [CrossRef]

40. Wang, Q.; Chen, J.; Huang, K.; Zhang, X.; Xu, L.; Shi, Z. guo Preparation, characterization and application of N-methylene phosphonic acid chitosan grafted magnesia-zirconia stationary phase. Anal. Chim. Acta 2015, 854, 191-201. [CrossRef]

41. Liew, J.W.Y.; Loh, K.S.; Ahmad, A.; Lim, K.L.; Daud, W.R. Effect of modified natural filler o-methylene phosphonic K-carrageenan on chitosan-based polymer electrolytes. Energies 2018, 11, 1910. [CrossRef]

42. Ma, G.; Qian, B.; Yang, J.; Hu, C.; Nie, J. Synthesis and properties of photosensitive chitosan derivatives(1). Int. J. Biol. Macromol. 2010, 46, 558-561. [CrossRef]

43. Mobarak, N.N.; Ahmad, A.; Abdullah, M.P.; Ramli, N.; Rahman, M.Y.A. Conductivity enhancement via chemical modification of chitosan based green polymer electrolyte. Electrochim. Acta 2013, 92, 161-167. [CrossRef]

44. Coates, J. Interpretation of Infrared Spectra, A Practical Approach. Encycl. Anal. Chem. 2006, 1-23. [CrossRef]

45. Andrade, G.; Barbosa-Stancioli, E.F.; Piscitelli Mansur, A.A.; Vasconcelos, W.L.; Mansur, H.S. Design of novel hybrid organicinorganic nanostructured biomaterials for immunoassay applications. Biomed. Mater. 2006, 1, 221-234. [CrossRef]

46. Andrade, G.I.; Barbosa-Stancioli, E.F.; Mansur, A.A.P.; Vasconcelos, W.L.; Mansur, H.S. Small-angle X-ray scattering and FTIR characterization of nanostructured poly (vinyl alcohol)/silicate hybrids for immunoassay applications. J. Mater. Sci. 2008, 43, 450-463. [CrossRef]

47. Wang, T.; Turhan, M.; Gunasekaran, S. Selected properties of pH-sensitive, biodegradable chitosan-poly(vinyl alcohol) hydrogel. Polym. Int. 2004, 53, 911-918. [CrossRef]

48. Mansur, H.S.; Sadahira, C.M.; Souza, A.N.; Mansur, A.A.P. FTIR spectroscopy characterization of poly (vinyl alcohol) hydrogel with different hydrolysis degree and chemically crosslinked with glutaraldehyde. Mater. Sci. Eng. C 2008, 28, 539-548. [CrossRef]

49. Shao, C.; Kim, H.Y.; Gong, J.; Ding, B.; Lee, D.R.; Park, S.J. Fiber mats of poly(vinyl alcohol)/silica composite via electrospinning. Mater. Lett. 2003, 57, 1579-1584. [CrossRef]

50. Lue, S.J.; Chen, J.Y.; Yang, J.M. Crystallinity and stability of poly(vinyl alcohol)-fumed silica mixed matrix membranes. J. Macromol. Sci. Part B Phys. 2008, 47, 39-51. [CrossRef]

51. Sapalidis, A.A. Porous Polyvinyl alcohol membranes: Preparation methods and applications. Symmetry 2020, 12, 960. [CrossRef]

52. Menard, K.P.; Bilyeu, B.W. Dynamic Mechanical Analysis of Polymers and Rubbers. Encycl. Anal. Chem. 2008. [CrossRef]

53. Turi, E.A. Thermal Characterization of Polymeric Materials; Academic Press: New York, NY, USA, 1997.

54. Ferry, J.D. Viscoelastic Properties of Polymers; John Wiley \& Sons: Hoboken, NJ, USA, 1980.

55. Boyer, R.F. Dependence of mechanical properties on molecular motion in polymers. Polym. Eng. Sci. 1968, 8, 161-185. [CrossRef]

56. Rohn, C.L. Analytical Polymer Rheology: Structure-Processing-Property Relationships; Hanser: Liberty Township, OH, USA, 1995.

57. Menard, K.P. Dynamic Mechanical Analysis. Encycl. Anal. Chem. 2017, 1-22. [CrossRef]

58. Du, L.; Yan, X.; He, G.; Wu, X.; Hu, Z.; Wang, Y. SPEEK proton exchange membranes modified with silica sulfuric acid nanoparticles. Int. J. Hydrogen Energy 2012, 37, 11853-11861. [CrossRef]

59. Kannan, R.; Kakade, B.A.; Pillai, V.K. Polymer electrolyte fuel cells using nafion-based composite membranes with functionalized carbon nanotubes. Angew. Chemie-Int. Ed. 2008, 47, 2653-2656. [CrossRef]

60. Kalaiselvimary, J.; Sundararajan, M.; Prabhu, M.R. Preparation and characterization of chitosan-based nanocomposite hybrid polymer electrolyte membranes for fuel cell application. Ionics 2018, 24, 3555-3571. [CrossRef]

61. Isahak, W.N.R.W.; Ismail, M.; Nordin, N.M.; Jahim, J.M.; Yarmo, M.A. Synthesis, characterization and catalytic performance of H 3SiW 12O 40/SiO 2 prepared by sol-gel technique. J. Nanotechnol. 2011, 2011, 13194-13203. [CrossRef]

62. Lakshminarayana, G.; Nogami, M. Synthesis and characterization of proton conducting inorganic-organic hybrid nanocomposite membranes based on tetraethoxysilane/trimethylphosphate/3-glycidoxypropyltrimethoxysilane/heteropoly acids. Electrochim. Acta 2009, 54, 4731-4740. [CrossRef] 
63. Shanmugam, S.; Viswanathan, B.; Varadarajan, T.K. Synthesis and characterization of silicotungstic acid based organic-inorganic nanocomposite membrane. J. Memb. Sci. 2006, 275, 105-109. [CrossRef]

64. Joni, I.M.; Nulhakim, L.; Vanitha, M.; Panatarani, C. Characteristics of crystalline silica (SiO2) particles prepared by simple solution method using sodium silicate (Na2SiO3) precursor. J. Phys. Conf. Ser. 2018, 1080. [CrossRef]

65. Liu, H.; Gong, C.; Wang, J.; Liu, X.; Liu, H.; Cheng, F.; Wang, G.; Zheng, G.; Qin, C.; Wen, S. Chitosan/silica coated carbon nanotubes composite proton exchange membranes for fuel cell applications. Carbohydr. Polym. 2016, 136, 1379-1385. [CrossRef]

66. Ou, Y.; Tsen, W.C.; Gong, C.; Wang, J.; Liu, H.; Zheng, G.; Qin, C.; Wen, S. Chitosan-based composite membranes containing chitosan-coated carbon nanotubes for polymer electrolyte membranes. Polym. Adv. Technol. 2018, 29, 612-622. [CrossRef]

67. Ou, Y.; Tsen, W.C.; Jang, S.C.; Chuang, F.S.; Wang, J.; Liu, H.; Wen, S.; Gong, C. Novel composite polymer electrolyte membrane using solid superacidic sulfated zirconia-Functionalized carbon nanotube modified chitosan. Electrochim. Acta 2018, 264, 251-259. [CrossRef]

68. Ciu, W.; Du, F.; Zhao, J.; Zhang, W.; Yang, Y.; Xie, X.; Mai, Y.W. Improving thermal conductivity while retaining high electrical resistivity of epoxy composites by incorporating silica-coated multi-walled carbon nanotubes. Carbon 2011, 49, 495-500. [CrossRef]

69. Gong, C.; Zheng, X.; Liu, H.; Wang, G.; Cheng, F.; Zheng, G.; Wen, S.; Law, W.C.; Tsui, C.P.; Tang, C.Y. A new strategy for designing high-performance sulfonated poly(ether ether ketone) polymer electrolyte membranes using inorganic proton conductor-functionalized carbon nanotubes. J. Power Sources 2016, 325, 453-464. [CrossRef]

70. Wong, C.Y.; Wong, W.Y.; Walvekar, R.; Loh, K.S.; Khalid, M.; Lim, K.L. Effect of deep eutectic solvent in proton conduction and thermal behaviour of chitosan-based membrane. J. Mol. Liq. 2018, 269, 675-683. [CrossRef]

71. Xie, Z.; Wu, H.; Wu, Q.; Ai, L. Synthesis and performance of solid proton conductor molybdovanadosilicic acid. RSC Adv. 2018, 8, 13984-13988. [CrossRef]

72. Vijayalekshmi, V.; Khastgir, D. Fabrication and comprehensive investigation of physicochemical and electrochemical properties of chitosan-silica supported silicotungstic acid nanocomposite membranes for fuel cell applications. Energy 2018, 142, 313-330. [CrossRef]

73. Gnana Kumar, G.; Lee, D.N.; Kim, P.; Nahm, K.S.; Nimma Elizabeth, R. Characterization of PVdF-HFP/Nafion/AlO[OH]n composite membranes for direct methanol fuel cell (DMFC). Eur. Polym. J. 2008, 44, 2225-2230. [CrossRef]

74. Kumar, P.; Kundu, P.P. Coating and lamination of Nafion117 with partially sulfonated PVdF for low methanol crossover in DMFC applications. Electrochim. Acta 2015, 173, 124-130. [CrossRef]

75. Xue, Y.; Chan, S. Layer-by-layer self-assembly of CHI/PVS-Nafion composite membrane for reduced methanol crossover and enhanced DMFC performance. Int. J. Hydrogen Energy 2015, 40, 1877-1885. [CrossRef]

76. Hasani-Sadrabadi, M.M.; Dashtimoghadam, E.; Majedi, F.S.; Wu, S.; Bertsch, A.; Moaddel, H.; Renaud, P. Nafion/chitosanwrapped CNT nanocomposite membrane for high-performance direct methanol fuel cells. RSC Adv. 2013, 3, 7337-7346. [CrossRef]

77. Wong, C.Y.; Wong, W.Y.; Loh, K.S.; Khalid, M.; Wan Daud, W.R.; Lim, K.L.; Walvekar, R. Influences of crosslinked carboxylic acid monomers on the proton conduction characteristics of chitosan/SPVA composite membranes. Polymer 2020, $203,122782$. [CrossRef]

78. Gaur, S.S.; Dhar, P.; Sonowal, A.; Sharma, A.; Kumar, A.; Katiyar, V. Thermo-mechanically stable sustainable polymer based solid electrolyte membranes for direct methanol fuel cell applications. J. Memb. Sci. 2017, 526, 348-354. [CrossRef]

79. Aziz, N.A.; Majid, S.R.; Arof, A.K. Synthesis and characterizations of phthaloyl chitosan-based polymer electrolytes. J. Non-Cryst. Solids 2012, 358, 1581-1590. [CrossRef] 